\title{
The regional-scale surface mass balance of Pine Island Glacier, West Antarctica, over the period 2005-2014, derived from airborne radar soundings and neutron probe measurements
}

\author{
Stefan Kowalewski ${ }^{1}$, Veit Helm ${ }^{1}$, Elizabeth Mary Morris ${ }^{2}$, and Olaf Eisen ${ }^{1}$ \\ ${ }^{1}$ Alfred Wegener Institute, Helmholtz Centre for Polar and Marine Research, Bremerhaven, Germany \\ ${ }^{2}$ Scott Polar Research Institute, University of Cambridge, Cambridge, UK
}

Correspondence: Stefan Kowalewski (stefan.kowalewski@awi.de)

Received: 9 April 2020 - Discussion started: 8 June 2020

Revised: 9 December 2020 - Accepted: 17 January 2021 - Published: 11 March 2021

\begin{abstract}
We derive recent surface mass balance (SMB) estimates from airborne radar observations along the iSTAR traverse $(2013,2014)$ at Pine Island Glacier (PIG), West Antarctica. Ground-based neutron probe measurements provide information of snow and firn density with depth at 22 locations and were used to date internal annual reflection layers. The 2005 layer was traced for a total distance of $2367 \mathrm{~km}$ to determine annual mean SMB for the period 2005-2014. Using complementary SMB estimates from two regional climate models, RACMO2.3p2 and MAR, and a geostatistical kriging scheme, we determine a regional-scale SMB distribution with similar main characteristics to that determined for the period 1985-2009 in previous studies. Local departures exist for the northern PIG slopes, where the orographic precipitation shadow effect appears to be more pronounced in our observations, and the southward interior, where the SMB gradient is more pronounced in previous studies. We derive total mass inputs of $79.9 \pm 19.2$ and $82.1 \pm 19.2 \mathrm{Gt} \mathrm{yr}^{-1}$ to the PIG basin based on complementary ASIRAS-RACMO and ASIRAS-MAR SMB estimates, respectively. These are not significantly different to the value of $78.3 \pm 6.8 \mathrm{Gt} \mathrm{yr}^{-1}$ for the period 1985-2009. Thus, there is no evidence of a secular trend at decadal scales in total mass input to the PIG basin. We note, however, that our estimated uncertainty is more than twice the uncertainty for the 1985-2009 estimate on total mass input. Our error analysis indicates that uncertainty estimates on total mass input are highly sensitive to the selected krige methodology and assumptions made on the interpolation error, which we
\end{abstract}

identify as the main cause for the increased uncertainty range compared to the 1985-2009 estimates.

\section{Introduction}

The stability of the West Antarctic Ice Sheet (WAIS) is a major concern for scientists seeking to predict global sea level rise. Transport of heat from upwelling circumpolar deep water has proved to be a critical driver of Antarctic ice shelf thinning and grounding line retreat, thus initiating the acceleration of marine-terminating outlet glaciers (e.g. Hillenbrand et al., 2017). In particular the Amundsen Sea sector has experienced an unprecedented acceleration in ice discharge since the beginning of satellitebased ice flow observations in the 1970s. Three-quarters of this ice discharge stems from the Thwaites and Pine Island glaciers, with both showing evidence of rapid acceleration since the 1970s (Mouginot et al., 2014) and spreading of surface lowering along their tributaries over the past two decades (Konrad et al., 2017). While spaceborne observations indicate that this acceleration has levelled off recently (Rignot et al., 2019), they also support model projections suggesting modest changes in mass balance, i.e. the resulting net ice loss after accounting for all loss and gain processes, for the next decades to come (Bamber and Dawson, 2020). The dynamic ice loss is mainly responsible for the negative mass balance of Pine Island Glacier (PIG). The net input is commonly referred to as the surface mass balance (SMB), i.e. snowfall minus sublimation, meltwater 
runoff, and erosion/deposition of snow (Lenaerts et al., 2012; Medley et al., 2013). Various methods exist to measure the SMB on the ground (Eisen et al., 2008). The remoteness of WAIS makes such measurements logistically challenging, in particular when extending these measurements to regional scales. Basin-wide total mass input estimates strongly depend on the coverage and quality of SMB measurements. The study of Medley et al. (2014), hereinafter abbreviated as ME14, presents the first comprehensive survey of mean annual SMB between 1985 and 2009/2010 from airborne radar-based observations of the Thwaites and Pine Island glaciers. The authors demonstrated that such airborne radar observations provide a critical means to overcome logistical challenges. However, these measurements rely on assumptions about the dielectric properties of snow and firn, which include knowledge of their vertical density profiles. In this sense, ground-truthing measurements remain an important tool for calibrating the radar soundings.

As part of the iSTAR Ice Sheet Stability Programme, a traverse across the Pine Island Glacier (PIG) was carried out in 2013/2014 (T1) and repeated the year after (T2). In total 22 sites were occupied during both traverses. Boreholes of at least $13 \mathrm{~m}$ depth were drilled at each site during traverse T1. Density-depth profiles were measured with a neutron probe (NP) device during both traverses (Morris et al., 2017), and supplementary analysis of firn cores was performed for 10 sites during traverse $\mathrm{T} 2$ to determine additional independent proxies related to the annual snow accumulation (Konrad et al., 2019).

The Alfred Wegener Institute (AWI) contributed to the iSTAR traverse T2 with radar soundings from the Airborne SAR/Interferometric Radar Altimeter System (ASIRAS) aboard the Polar 5 research plane. Previous ASIRAS missions have demonstrated its capability to track annual snow accumulation layers of the upper firn column at regional scales over Greenland (Hawley et al., 2006; Overly et al., 2016). The PIG flight track connects all iSTAR sites so that internal annual snow accumulation layers can be traced to make regional-scale SMB estimates. By comparison with earlier SMB measurements at PIG, the vertical profiling based on the ASIRAS soundings achieves a resolution that is 1 order of magnitude higher (Table 1), which helps to trace narrow internal snow accumulation layers. In addition, the ASIRAS flight track contains several crossovers, which we used to validate the same isochronal reflector from different directions.

In this study we first address local departures between SMB estimates from ASIRAS and NP measurements to evaluate the uncertainty of our regional-scale ASIRAS SMB estimates. We then compare our results with those reported by ME14 and discuss differences between both data sets. Finally, we apply our new regional-scale SMB estimates to different PIG mass balance inventories to evaluate their impact in light of the current stability of the study area. We include a list of abbreviations and notations in Appendix A.

\section{Data and methods}

\section{1 iSTAR traverse}

The iSTAR traverse followed the PIG main trunk as well as its tributaries as shown in Fig. 1. A total flight track (black lines) of $2486 \mathrm{~km}$ was covered by the ASIRAS measurements between 1 and 3 December 2014. Following ME14, the basin outlines (dashed lines) include the Wedge zone between PIG and Thwaites. The main emphasis of the iSTAR campaign was on the fast-flowing segments of PIG; thus we lack measurements from the southward interior. Earlier observations from ME14 suggest that the SMB decreases towards the interior so the contribution from this area to the total mass input will be less than that from the rest of the basin.

Additional SMB measurements were made with a groundpenetrating radar (GPR) during traverse T1 and published in Konrad et al. (2019). The authors selected the $\sim 1986$ reflection layer, which approximately coincides with the observed main reflector by ME14, and traced the layer along sections of the $900 \mathrm{~km}$ traverse, amounting to a total of a $613 \mathrm{~km}$ distance covered by GPR observations. The route of these observations closely follows the ASIRAS flight track, and both are available at http://gis.istar.ac.uk/ (last access: 24 February 2021). Due to the limited maximum sampling depth of the ASIRAS and NP measurements, the 1985/1986 reflection layer used by ME14 and Konrad et al. (2019) is not contained in most of our data. To benefit from the ASIRAS coverage while simultaneously accounting for its limited depth range, we manually traced the continuous 2005 reflection layer over a distance of $2367 \mathrm{~km}$ to derive mean annual SMB estimates for the 2005-2014 period. Due to the reported consistency between the GPR and airborne SMB measurements in Konrad et al. (2019), we limit the comparison of our results to the basin-wide estimates by ME14. In addition, we assume that the effect of strain history, which could affect our SMB estimates at the fast-flowing sections of PIG, is negligible. Konrad et al. (2019) conclude that the total effect over the whole catchment is small, even though it can have a very significant effect at some sites. However, this effect is expected to be further reduced for the shallower reflection layer depths from the ASIRAS measurements.

\subsection{Neutron probe measurements}

NP measurements of snow and firn density were performed at all stations during both traverses as described in Morris et al. (2017). Further details on the calibration procedure, which is based on theoretical considerations, can be found in Morris (2008). A comparison with gravimetric density measurements at existing core profiles did not indicate a systematic bias between both measurement methods. To evaluate the effect of densification, the ground team repeated 


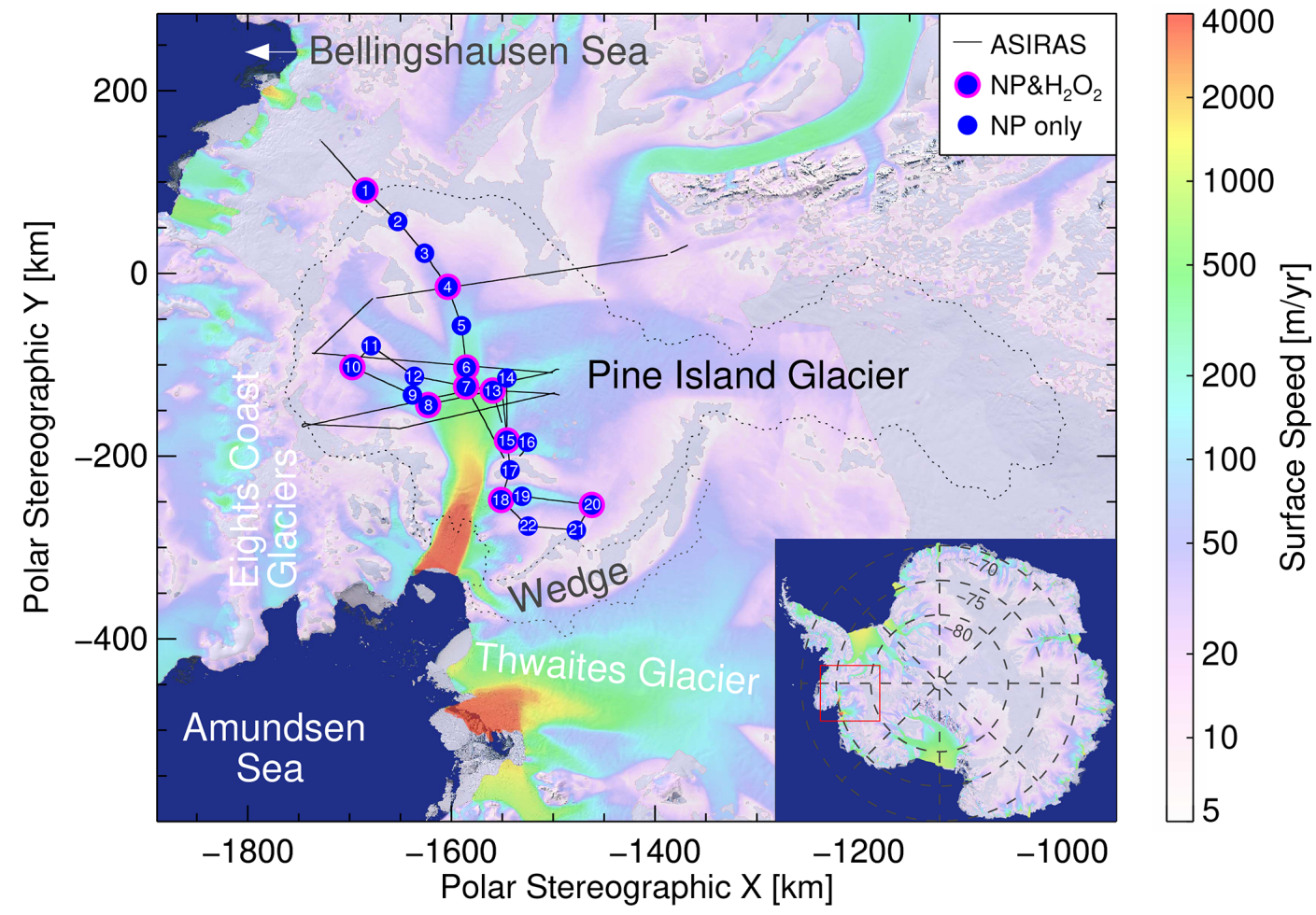

Figure 1. ASIRAS-iSTAR survey projected on polar stereographic coordinates: black lines denote the ASIRAS flight track, numbered blue circles the iSTAR sites with shallow $(\sim 13 \mathrm{~m})$ neutron probe snow density measurements, and magenta-blue circles iSTAR sites with additional deep $(\sim 50 \mathrm{~m})$ firn core measurements of $\mathrm{H}_{2} \mathrm{O}_{2}$ during traverse T2. Surface flow speeds from Rignot et al. (2017) are overlaid by colour shadings on top of Landsat imagery (U.S. Geological Survey, 2007). Dotted lines denote basin outlines based on Fretwell et al. (2013) analysis (data accessed via the SCAR Antarctic Digital Database on 23 April 2019).

Table 1. Approximate sample bin resolution and maximum depth of SAR level_1b processed ASIRAS data with indicated standard deviation of the vertical range bin based on the two-way-travel time (TWT)-to-depth conversion of this study, CReSIS accumulation radar according to M14, and pulseEKKO PRO GPR discussed in Konrad et al. (2019). For the GPR system we estimate the maximum sampling depths based on shared radargrams, which resolve the internal stratigraphy at PIG for TWTs up to (1000-1200) ns. Additional information includes the considered averaging periods, density profiles, and type of annual dating markers for each study.

\begin{tabular}{|c|c|c|c|}
\hline Radar system & $\begin{array}{l}\text { ASIRAS } \\
\text { (this study) }\end{array}$ & $\begin{array}{l}\text { CReSIS Accu-R } \\
\text { (M14) }\end{array}$ & $\begin{array}{l}\text { pulseEKKO PRO } \\
\text { (Konrad et al., 2019) }\end{array}$ \\
\hline Operation & airborne & airborne & ground based \\
\hline SMB averaging period & 2005-2014 & 1985-2009 & $1986-2014$ \\
\hline Density profiles & iSTAR NP & ITASE and 2010 cores & iSTAR cores \\
\hline Dating markers & $\begin{array}{l}\text { density guided } \\
\text { with } \mathrm{H}_{2} \mathrm{O}_{2}\end{array}$ & $\begin{array}{l}\mathrm{H}_{2} \mathrm{O}_{2} \text {, water isotope ratios, } \\
\text { non-sea-salt-sulfur-to-sodium ratio }\end{array}$ & $\mathrm{H}_{2} \mathrm{O}_{2}$ \\
\hline Vertical range bin (firn) & $7.3 \pm 0.3 \mathrm{~cm}$ & $62 \mathrm{~cm}$ & $100 \mathrm{~cm}$ \\
\hline Along-track bin & $4.5 \mathrm{~m}$ & order of $10 \mathrm{~m}$ & $1.4 \mathrm{~m}$ \\
\hline Maximum sampling depth & $30 \mathrm{~m}$ & $300 \mathrm{~m}$ & $(90-120) \mathrm{m}$ \\
\hline
\end{tabular}

the density profiling in the same boreholes during traverse $\mathrm{T} 2$. Because the most recent accumulation is missing in these profiles, they drilled an additional borehole of less than $6 \mathrm{~m}$ depth and a nearby distance of about $1 \mathrm{~m}$ to capture it during traverse T2. The only exception is site 2 , where the ground team decided to auger a completely new $14 \mathrm{~m}$ borehole for the density profiling due to poor data from the T1 hole.
The deep firn cores $(\sim 50 \mathrm{~m})$ shown in Fig. 1 were collected and analysed by the British Antarctic Survey. This analysis includes the annual variations with depth of the photochemical $\mathrm{H}_{2} \mathrm{O}_{2}$ tracer and density, which are phase shifted by about 6 months. According to Morris et al. (2017) the annual density variation is caused by the alternating late austral summer/autumn low-density hoar layer with 


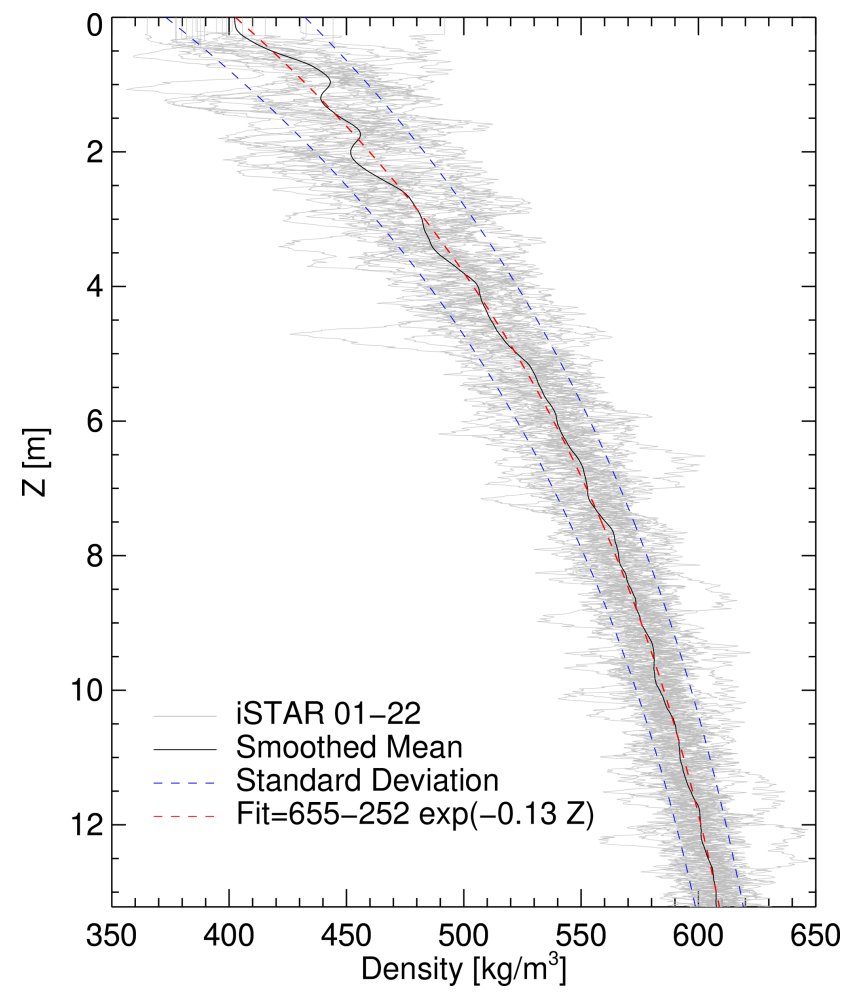

Figure 2. Compiled density-depth profiles from traverse $\mathrm{T} 2$ at all 22 iSTAR sites (grey lines). The black line denotes the smoothed mean profile, the red dashed line an exponential fit (units according to axis annotations), and the blue dashed lines the standard deviation intervals of the fit.

winter snow which has densified under the influence of warm summer temperatures. The different processes, which modulate the density and $\mathrm{H}_{2} \mathrm{O}_{2}$ concentration with depth, allow for an independent determination of annual snow accumulation at the 10 deep core sites. No volcanic reference horizon was detected in the cores (Robert Mulvaney, personal communication, 2020), which therefore limits the annual markers to the $\mathrm{H}_{2} \mathrm{O}_{2}$ and density profiles. Morris et al. (2017) applied an automatic annual layer identification routine to the vertical density profiles and used the annual $\mathrm{H}_{2} \mathrm{O}_{2}$ peak depths as an additional guidance for the annual layer dating. Thus, the depth-age scales from both annual markers are consistent.

We use a single regional density-depth profile we derive from the NP profiles of traverse T2 for the two-way-travel time (TWT)-to-depth conversion of the ASIRAS soundings. First, we merge the $\sim 13 \mathrm{~m}$ and nearby $\sim 6 \mathrm{~m}$ density-depth profiles at each site (except at site 2 ) by linearly relaxing their overlapping segments. To reduce the effect of lateral noise convolution, we limit the relaxation length to the overlapping segments that correlate well with each other. Then we align the intercepting depth-age scales to create a consistent depth-age scale for each compiled profile. The resulting 21 merged profiles and the single profile at site 2

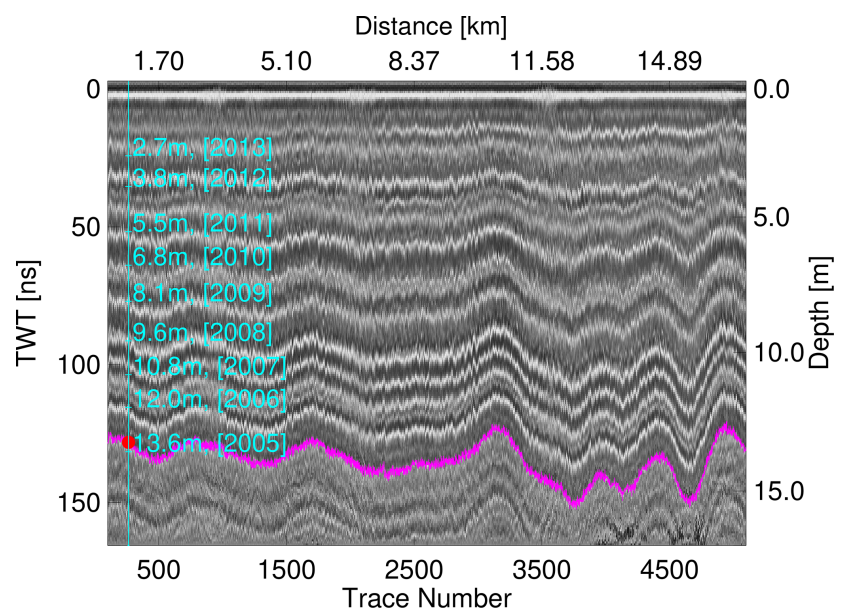

Figure 3. ASIRAS radargram at iSTAR site 21 with surface snow reflection centred at the origin of the TWT scale. The traced internal reflection layer is highlighted in magenta; annual markers from the NP profile at the point of closest approach are highlighted in cyan. The distance and trace numbers refer to the origin of the ASIRAS track segment 20156124 (see Table 2).

are shown by the grey lines in Fig. 2. From these 22 profiles, we then determine a smoothed regional mean profile, which is denoted by the black line. Morris et al. (2017) observed a two-stage Herron and Langway (1980) type densification at PIG, with the stages separated by an additional transition zone. We achieve a good fit to our regional mean profile with a simple exponential function (red dashed line, Fig. 2), which we apply to the TWT-to-depth conversion. The blue dashed lines show the fitted standard deviation of the density as a function of depth. Following Medley et al. (2013), we consider the fitted standard deviation to be representative of the spatial uncertainty of the regional-scale density-depth profile.

\subsection{ASIRAS soundings}

ASIRAS is a Ku-band radar altimeter which operates at a carrier frequency of $13.5 \mathrm{GHz}$ and a bandwidth of $1 \mathrm{GHz}$ (Mavrocordatos et al., 2004). It was set to low-altitude mode (designed for heights less than $1500 \mathrm{~m}$ above ground) during its measurements at PIG. A synthetic aperture radar (SAR) processing of the collected data was performed, which yields the spatial resolution of the SAR level_1b data shown in Table 1. The associated cross-track footprint is $\sim 15 \mathrm{~m}$. We use the electromagnetic wave speed $v=c / \sqrt{\epsilon^{\prime}}$ to convert TWT to depth, where $c$ is the vacuum speed of light and $\epsilon^{\prime}$ is the real part of the dielectric permittivity of the firn column. For the latter, we apply the commonly used empirical relation by Kovacs et al. (1995):

$\epsilon_{\mathrm{kov}}^{\prime}=\left(1+0.845 \rho_{\mathrm{s}}\right)^{2}$, 
where $\rho_{\mathrm{s}}=\rho / \rho_{\mathrm{w}}$ is the specific gravity of snow (or firn) at current depth with respect to the water density $\rho_{\mathrm{w}}=1000 \mathrm{~kg} \mathrm{~m}^{-3}$. An alternative model by Looyenga (1965) is

$\epsilon_{\mathrm{loo}}^{\prime}=\left(\frac{\rho}{\rho_{\text {ice }}}\left[\sqrt[3]{\epsilon_{\mathrm{ice}}^{\prime}}-1\right]+1\right)^{3}$,

with $\epsilon_{\text {ice }}^{\prime}=3.17$ (Evans, 1965) and $\rho_{\text {ice }}=917 \mathrm{~kg} \mathrm{~m}^{-3}$. Sinisalo et al. (2013), who consider a similar depth range to this study, conclude that the difference between wave speeds based on Eqs. (1) and (2) has a negligible impact on their SMB estimates. This is also the case for our estimates (see Sect. 3). The maximum depth of the radargrams is $\sim$ $30 \mathrm{~m}$ based on the TWT-to-depth conversion from the fitted regional mean profile of density with depth and substituted Kovacs relation. The depth range of resolved internal stratigraphy varies along the flight track, but the layering remains visible for most of the upper $13 \mathrm{~m}$ depth covered by the NP measurements. Using the regional mean profile of density with depth, we determine the water equivalent (w.e.) depth value for each waveform bin and calculate the mass per unit area between the selected reflection layer (magenta line in Fig. 3) and surface. We assume that internal reflection layers are generated by the dielectric contrast at embedded thin ice and hoar layers (Arcone et al., 2004, 2005) and that these layers are formed at regional scales around summer/autumn (Medley et al., 2013). These layers may coincide with the annual density modulation, which we observe with the NP measurements.

Before the layer tracing, we apply an automatic-gaincontrol filter to all waveforms and limit their dynamic range to twice the standard deviation centred around the mean amplitude of each waveform. This improved the signal contrast of the radargram. Initially we tested a phasefollowing algorithm of the Paradigm EPOS geophysical processing software to trace the selected reflection layer semi-automatically. However, this method became unstable for lower contrast and cases with close layer spacing. Furthermore, remaining SAR-processing artefacts were interfering with the phase-following algorithm. Because of the complex nature of the observed stratigraphy, as has been also reported by Konrad et al. (2019), manual layer tracing was used. Following Richardson et al. (1997), we attempted to bridge distorted or merged layer segments whenever distinct characteristics of a vertical layer sequence could be identified with confidence before and after the bridging. Different processes can lead to distortion of the reflection layers, e.g. processes changing deposition of the annual snow layers or excessive rolling angles of the aeroplane, while merging layers can result from low snow precipitation and ablative processes (e.g. wind scouring) or a combination of both. We checked the traced layer for possible mismatches which may have resulted from systematic errors in the initial manual layer tracing at 34 crossover points and 8 nearby flight track segments. Such mismatches were particularly observed along challenging profile sections and corrected by retracing the reflection layers, which yield the best match at the crossover points. In this sense, the layer tracing is performed independently from the annual layer dating at each iSTAR site.

\subsection{Measurement error estimation}

We attempt to trace the 2005 reflection layer, which is covered by all NP density-depth profiles. So far, we assumed that internal reflection layers form on an annual basis during summer/autumn, but the potential formation of intraannual reflection layers may challenge this assumption. For instance, Nicolas et al. (2017) found evidence of surface melt episodes over large parts of WAIS in response to warm air intrusion events. Scott et al. (2010) observed a strong reflection layer, which coincides with an exceptional melt layer at $22 \mathrm{~m}$ depth at one PIG ice core location. These findings suggest that intra-annual reflection layers can form at the basin scale, even though the formation is less frequent, as it appears to be related to the complex coupling between different atmospheric modes (e.g. Nicolas et al., 2017; Donat-Magnin et al., 2020). The frequency of intraannual reflection layer formation may change towards the coast, where the snow accumulation is high. For instance, Fig. 3 shows additional reflection layers with respect to the annual density markers from the NP measurements at site 21. Extreme solid precipitation events may also impact the density modulation with depth (Turner et al., 2019), which is considered for the depth-age scale based on the NP measurements. Snow erosion may remove annual markers where accumulation rates are low. In addition to annual layer counting errors, the timing between the reflection layer formation and snow densification may be offset during summer/autumn. All these factors challenge the tracing and dating of the 2005 reflection layer, but combining the stratigraphic information from the ASIRAS and iSTAR observations helps reduce the risk of systematic errors from erroneous layer counting. To account for the remaining risk in terms of isochronal accuracy, we assign an annual layer tracing uncertainty of $\overline{\delta t}= \pm 1$ years.

Following Morris et al. (2017), we define mass balance years between the density peaks in the NP profiles (nominally 1 July). For instance, the mass balance year 2013 begins at the second annual density peak below the surface (nominally 1 July 2013) and ends at the first peak (1 July 2014). Based on annual density markers, we can relate the snow and firn depth at each iSTAR site to its associated age and determine the reflection layer age from its depth at each cross section. Here, we use an exponential fit of the local density-depth profile for the TWT-to-depth conversion. The lateral displacement $\Delta D$ between the point of closest approach of the flight track and iSTAR site adds to the reflection layer dating uncertainty. We therefore consider 
Table 2. Dated reflection layer year at nearby iSTAR sites. "Track number" refers to the ASIRAS flight track naming convention (year of measurement season (four digits), measurement type (one digit), profile segment number (three digits)); iSTAR site elevation in metres above ellipsoid (m a.e.) with respect to the ITRF08(2015) reference framework; $\Delta D$ is the closest distance between the ASIRAS track and iSTAR site, and $N$ is the number of picking samples considered for layer dating. Years in brackets are discarded from the regional layer age estimation due to (i) significant departure between traced layer and depth-age scale at site 2 (see main text), (ii) layer gaps due to high noise levels in the radargram, and (iii) the layer significantly exceeding the dated NP profile depth (values in brackets indicate extrapolated depth-age values).

\begin{tabular}{|c|c|c|c|c|c|c|c|c|}
\hline $\begin{array}{l}\text { Track } \\
\text { number }\end{array}$ & $\begin{array}{r}\text { iSTAR } \\
\text { site }\end{array}$ & $\begin{array}{r}\text { Latitude } \\
{\left[{ }^{\circ}\right]}\end{array}$ & $\begin{array}{r}\text { Longitude } \\
{\left[^{\circ}\right]}\end{array}$ & $\begin{array}{r}\text { Elevation } \\
\text { [ma.e.] }\end{array}$ & Year & $\begin{array}{l}\Delta D \\
{[\mathrm{~m}]}\end{array}$ & $N$ & Comment \\
\hline 20156125 & 1 & -74.565 & -86.913 & 1362 & $2003.9 \pm 0.2$ & 75 & 51 & \\
\hline 20156125 & 2 & -74.865 & -88.030 & 1195 & $(2009.88 \pm 0.03)$ & 8 & 5 & erroneous NP dating \\
\hline 20156125 & 3 & -74.111 & -89.224 & 1032 & $2003.39 \pm 0.04$ & 11 & 7 & \\
\hline 20156125 & 4 & -75.319 & -90.524 & 860 & $2004.9 \pm 0.1$ & 86 & 55 & \\
\hline 20156110 & 4 & & $\vdots$ & $\vdots$ & $2004 \pm 1$ & 811 & 422 & \\
\hline 20156125 & 5 & -75.431 & -92.060 & 798 & $2006.4 \pm 0.1$ & 119 & 67 & \\
\hline 20156125 & 6 & -75.456 & -93.718 & 708 & $2005.1 \pm 0.2$ & 177 & 121 & \\
\hline 20156106 & 6 & & & & $2006.0 \pm 0.6$ & 2000 & 856 & \\
\hline 20156125 & 7 & -75.440 & -94.460 & 679 & missing & 226 & & noise \\
\hline 20156115 & 7 & $\vdots$ & $\vdots$ & . & $2006.3 \pm 0.4$ & 304 & 251 & \\
\hline 20156113 & 8 & -75.090 & -95.070 & 708 & $2004.8 \pm 0.2$ & 316 & 149 & \\
\hline 20156109 & 8 & & & & $2004.9 \pm 0.2$ & 470 & 277 & \\
\hline 20156113 & 9 & -74.956 & -94.631 & 733 & $2003.1 \pm 0.1$ & 282 & 129 & \\
\hline 20156113 & 10 & -74.442 & -93.448 & 867 & $2003.6 \pm 0.4$ & 9 & 5 & \\
\hline 20156114 & 10 & & $\vdots$ & & $2004.9 \pm 0.1$ & 331 & 120 & \\
\hline 20156114 & 11 & -74.620 & -92.700 & 909 & $2004.3 \pm 0.2$ & 121 & 37 & \\
\hline 20156115 & 11 & & $\vdots$ & : & $2004.3 \pm 0.2$ & 76 & 57 & \\
\hline 20156115 & 12 & -74.998 & -93.930 & 762 & missing & 490 & & noise \\
\hline 20156115 & 13 & -75.670 & -94.690 & 691 & $2005.5 \pm 0.2$ & 127 & 71 & \\
\hline 20156102 & 13 & $\vdots$ & $\vdots$ & & $2005.7 \pm 0.2$ & 56 & 35 & \\
\hline 20156109 & 13 & $\vdots$ & $\vdots$ & $\vdots$ & $2004.7 \pm 0.1$ & 377 & 102 & \\
\hline 20156107 & 14 & -75.805 & -94.231 & 749 & $2003.5 \pm 1$ & 325 & 171 & \\
\hline 20156109 & 14 & & & & $2005.0 \pm 0.6$ & 350 & 174 & \\
\hline 20156107 & 15 & -75.750 & -96.730 & 712 & $2005.15 \pm 0.09$ & 485 & 257 & \\
\hline 20156120 & 15 & & $\vdots$ & $\vdots$ & $2005.92 \pm 0.2$ & 190 & 112 & \\
\hline 20156107 & 16 & -75.926 & -96.898 & 763 & $2004.19 \pm 0.05$ & 413 & 246 & \\
\hline 20156103 & 16 & & & & $2003.8 \pm 0.1$ & 314 & 181 & \\
\hline 20156120 & 17 & -75.740 & -97.930 & 716 & missing & 60 & & noise \\
\hline 20156121 & 18 & -75.617 & -99.073 & 527 & $2004.33 \pm 0.09$ & 186 & 98 & \\
\hline 20156120 & 18 & $\vdots$ & $\vdots$ & $\vdots$ & $(2003.2 \pm 0.2)$ & 297 & 143 & extrapolated \\
\hline 20156126 & 18 & & $\vdots$ & & $(2002.0 \pm 0.4)$ & 867 & 245 & extrapolated \\
\hline 20156121 & 19 & -75.803 & -99.048 & 704 & $(1996.8 \pm 0.3)$ & 230 & 44 & extrapolated \\
\hline 20156122 & 20 & -76.404 & -99.828 & 1096 & $2005.12 \pm 0.06$ & 15 & 2 & \\
\hline 20156122 & 21 & -76.224 & -100.770 & 1075 & $2005.73 \pm 0.02$ & 115 & 40 & \\
\hline 20156124 & 21 & & $\vdots$ & & $2005.71 \pm 0.07$ & 26 & 15 & \\
\hline 20156124 & 22 & -75.804 & -100.280 & 819 & $2005.65 \pm 0.06$ & 21 & 13 & \\
\hline
\end{tabular}


(a)

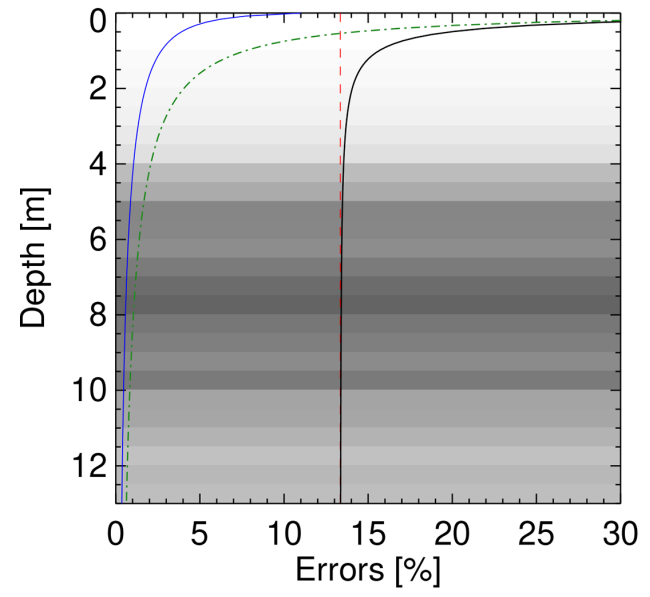

(c) (b)

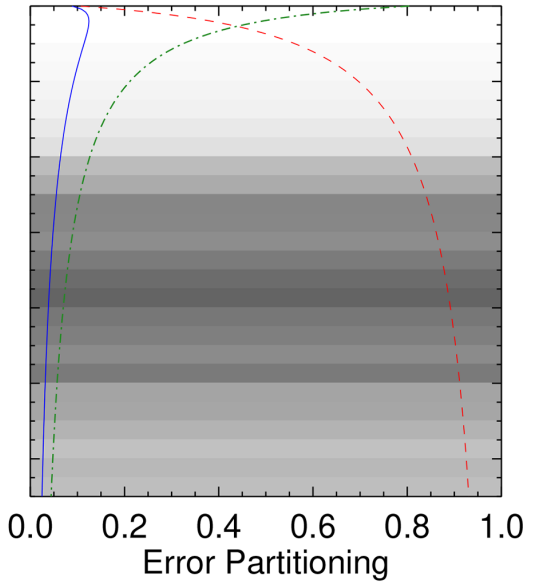

(d)

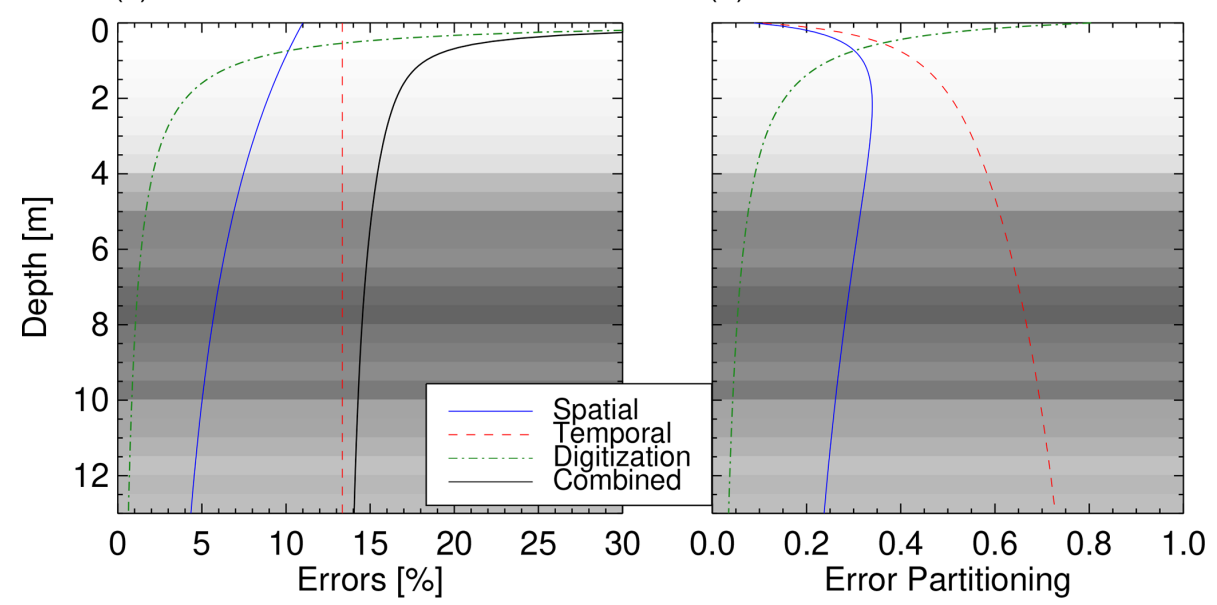

Figure 4. Spatial, temporal, digitization, and combined SMB measurement errors, which relate to the variability in density, dating uncertainty, and ASIRAS sampling accuracy, respectively: relative errors (a, c) and error partitioning (b, d). Grey background shades indicate the depth distribution of the traced 2005 reflection layer, with darker shading indicating higher number concentrations. (a, b) Based on error propagation according to Eq. (5). (c, d) Excluded spatial error cancellation in Eq. (5) (see main text) and considered for the final error estimation of this study.

all $N$ points which lie within a $2 \Delta D$ interval along the flight track. The interval is centred at the point of closest approach for the layer dating. Based on the local depth-age scale, we relate the estimated depths of $N$ points to their ages and assign the final layer date to their mean value. To account for the mass balance year definition above, we add 6 months to the mean layer date, which is listed for all iSTAR positions in Table 2. In addition, we estimate the dating uncertainty from the $N$ lateral estimates by their standard deviation $\sigma_{x}$. In this sense, our error estimate is more conservative than the standard error of the mean. Furthermore, we assume that the uncertainty due to local variation in the stratigraphy is isotropic, which does not generally need to be true. However, according to Table 2 the overall impact of this effect is 1 order of magnitude smaller than the variability of layer age values among all iSTAR sites in most cases. As indicated in Table 2, we excluded dating estimates around iSTAR sites 2 and 19. In both cases, our layer tracing revealed a large offset contrary to the neighbouring iSTAR sites. Possible reasons for these offsets could be systematic errors in the layer dating from the NP profiles, the variability of internal stratigraphy between the ASIRAS measurements and their closest approach to both iSTAR sites, or systematic errors in the manual reflection layer tracing. The remaining exclusion of layer age estimates at iSTAR sites 7, 12, and 18 is either due to high noise levels of the radargram or reflection layer depths significantly exceeding the NP depthage scales. Following Konrad et al. (2019) we estimate the final reflection layer year by the mean of dating values at each site with an uncertainty of $\Delta t=\sqrt{\overline{\delta t}^{2}+\delta \bar{t}^{2}+\bar{t}_{x}^{2}}$, with the standard deviation of dating estimates $\delta \bar{t}$ and the 
propagated error $\bar{t}_{x}=1 / n \sqrt{\sum_{i}^{n} \sigma_{x}(i)^{2}}$ from the $n$ lateral error estimates around each iSTAR site ( $i=$ site number), which we introduced in addition. The resulting reflection layer dating estimate is $T=2004.8 \pm 1.4$, which corresponds to a layer age of $a=10.1 \pm 1.4$. The associated average surface accumulation rate $\dot{b}$ in terms of w.e. depth per year is

$\dot{b}=\frac{1}{a \rho_{\mathrm{w}}} \sum_{i=1}^{m} \delta z_{i} \rho_{i}$,

where $\delta z_{i}$ is the $i$ th depth increment of the radar waveform and $\rho_{i}$ is the associated density. Substitution of the wave propagation speed for $\delta z_{i}$ yields

$\dot{b}=\frac{1}{a \rho_{\mathrm{w}}} \sum_{i=1}^{m} \frac{c t_{\mathrm{s}}}{\sqrt{\epsilon_{i}^{\prime}}} \rho_{i}$,

where $t_{\mathrm{s}}=0.37 \mathrm{~ns}$ is the ASIRAS vertical bin sampling time (i.e. $0.5 \times$ TWT per bin), and $\epsilon_{i}^{\prime}$ refers to the permittivity value at the $i$ th bin. To avoid any confusion with previous summations, the final index $m$ refers to the traced waveform bin at the reflection layer depth. It is evident from Eq. (4) that the spatial uncertainty of the density profile affects both the integration depth and incremental mass. Medley et al. (2013) and ME14 estimated the spatial uncertainty from the resulting SMB change by directly applying the standard deviation fits of their regional density profiles to the TWTto-SMB conversion. Instead, we may propagate the error in Eq. (4), assuming that errors are uncorrelated and normally distributed. Based on the Kovacs relation according to Eq. (1) we account for the temporal, spatial, and digitization error components:

$$
\Delta \dot{b}=\frac{c t_{\mathrm{s}}}{a \rho_{\mathrm{w}}} \sqrt{\underbrace{\sum_{i=1}^{m}\left(\frac{\Delta \rho_{i}}{\epsilon_{\mathrm{kov}, i}^{\prime}}\right)^{2}}_{\text {spatial }}+\underbrace{\left(\frac{\Delta a}{a} \sum_{j=1}^{m} \frac{\rho_{j}}{\sqrt{\epsilon_{\mathrm{kov}, j}^{\prime}}}\right)^{2}}_{\text {temporal }}+\underbrace{\left(\frac{1}{3} \sum_{k=m-1}^{m+1} \frac{\rho_{k}}{\sqrt{\epsilon_{\mathrm{kov}, k}^{\prime}}}\right)^{2}}_{\text {digitization }},}
$$

where $\Delta a= \pm 1.4$ years is the temporal uncertainty, and $\Delta \rho_{i}$ represents the standard deviation intervals according to Fig. 2. Due to the small incremental density change of $<0.7 \%$ along the entire profile, we approximate the digitization error by the mean SMB value of three consecutive bins centred at the final profile bin of the current integration depth. Figure 4 a displays the propagated individual measurement error components as well as the combined measurement error according to Eq. (5) as a function of geometric depth. In addition, we include the error partitioning in Fig. 4b. The grey background shades highlight the distribution of layer depths to visualize the relevant error range of our SMB estimates, which peaks around $(5,8$, and 10$) \mathrm{m}$ (darker shades). In comparison with Medley et al. (2013) and ME14, we find that our spatial error estimate based on Eq. (5) is reduced by about 1 order of magnitude, while the standard deviation fits of their regional density profiles cover a similar range compared to ours. We may ignore the spatial error compensation in Eq. (5) by replacing the root sum of squares (RSS) with absolute values:

$$
\sum_{i=1}^{m}\left(\Delta \rho_{i} / \epsilon_{\mathrm{kov}, i}^{\prime}\right)^{2} \rightarrow\left(\sum_{i=1}^{m}\left|\Delta \rho_{i} / \epsilon_{\mathrm{kov}, i}^{\prime}\right|\right)^{2} .
$$

Hence, to comply with the studies above, we consider the more conservative spatial error propagation based on the sum of absolute values, but we keep the RSS of individual error components for the combined measurement error estimate as shown in Fig. 4c-d. Following these assumptions, we find that our measurement error estimate is still dominated by the temporal layer dating uncertainty for most of the traced layer depths, but the spatial error reaches a similar range to that reported in Medley et al. (2013). We consider the combined measurement error based on Fig. $4 c-d$ for the SMB estimates of this study.

\subsection{Kriging scheme}

We focus on the regional-scale variability of the SMB distribution at PIG. Figure 5 shows our high-resolution (i.e. metre-scale) SMB estimates as well as smoothed SMB values with contour lines from a digital elevation model (DEM) by Helm et al. (2014). We use the same $25 \mathrm{~km}$ along-track smoothing window as ME14 and choose a sampling interval of half the smoothing window length. We initially tested the same interpolation scheme as described in ME14 to estimate a regional-scale SMB field for the PIG basin from our smoothed SMB points. This scheme is based on the ordinary kriging (OK) algorithm, a widely used geostatistical interpolation technique (e.g. Isaaks and Srivastava, 1991). Instead of a direct OK interpolation of smoothed SMB observations, ME14 consider the residual SMB values with regard to an ordinary least squares linear regression model for the Thwaites-PIG basin area with northing, easting, and elevation as explanatory variables. This, in turn, yields a small degree of skewness $<0.5$ with respect to the residual SMB distribution. However, we failed to reduce the skewness of residual SMB values from our estimates effectively using the same method, which may be due to the different aerial coverage considered in our regression model. Examination of the DEM contour lines in Fig. 5 reveals that a simple relation between surface elevation and SMB is not evident, which may hint that the prevailing synoptic-scale weather conditions at the Amundsen and Bellingshausen Sea sectors in combination with the precipitation shadowing effect of the mountain ranges of Eights Coast (Fig. 1) require a more sophisticated model to capture the SMB at the PIG basin scale. We therefore searched for an alternative approach to generate krige estimates from the SMB sample population of this study without the use of a regression model. Such alternative, 


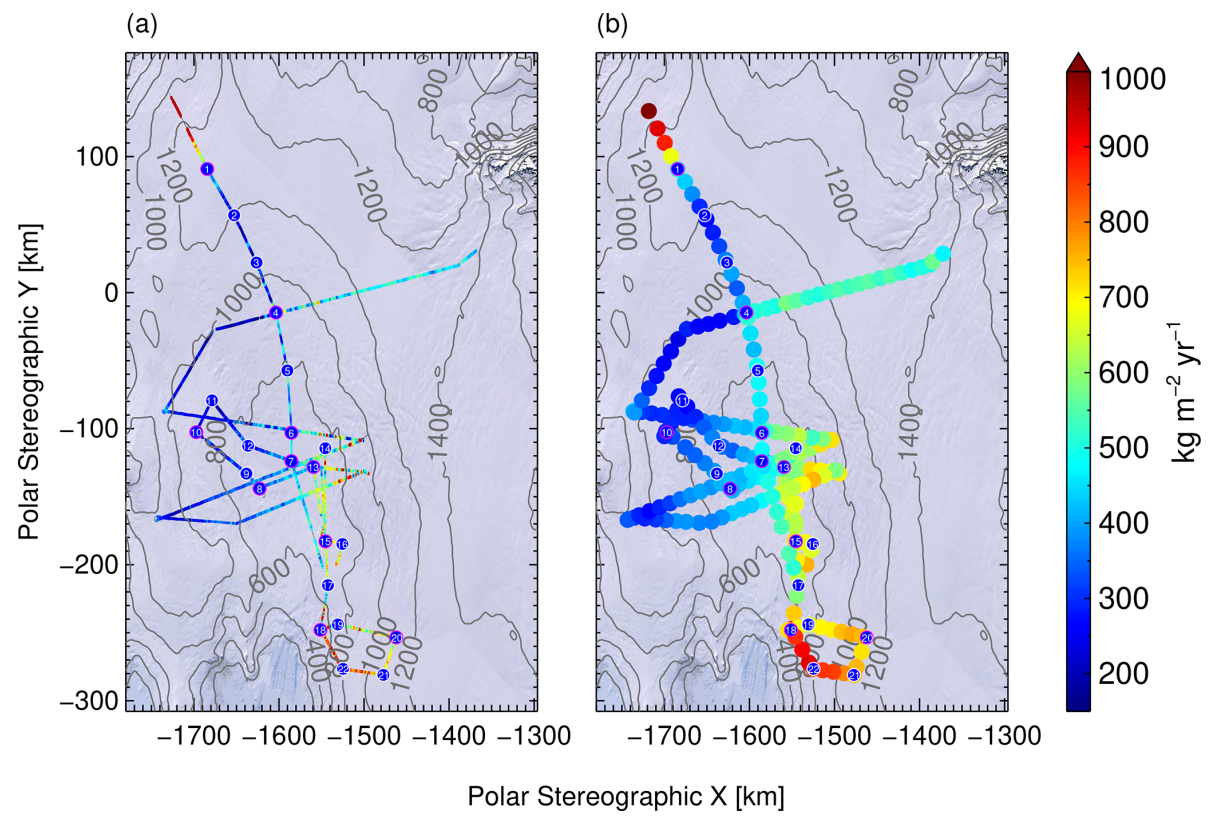

Figure 5. Traced annual mean SMB between November 2004 and December 2014 from ASIRAS soundings with overlaid contour lines in metres from a digital elevation model (Helm et al., 2014) and Landsat background imagery (U.S. Geological Survey, 2007). Circles with numbers denote the iSTAR sites. (a) High spatial SMB resolution; (b) smoothed and downsampled SMB estimates.

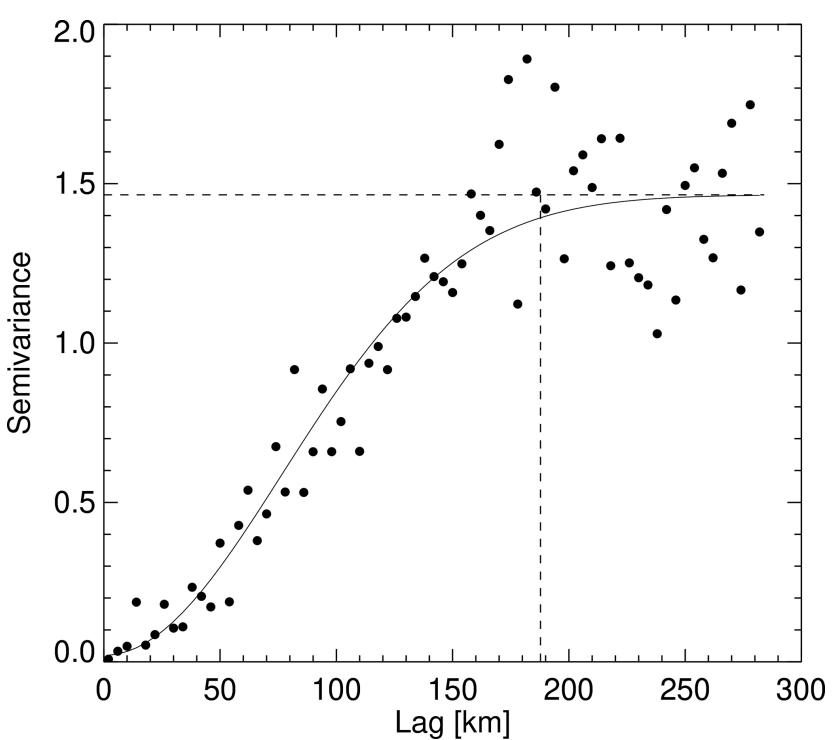

Figure 6. Experimental semivariogram of log-transformed smoothed SMB observations (dots), Gaussian fit model (black solid line), and sill and practical range parameter (dashed lines).

which is also mentioned in ME14, is a logarithmic transformation of the SMB observations prior to the OK interpolation:

$$
\dot{B}\left(x_{0}\right)=\ln \left(\dot{b}\left(x_{0}\right)+C\right),
$$

where $C$ is an arbitrary constant and $x_{0}$ represents the current interpolation location. After the $\mathrm{OK}$ interpolation

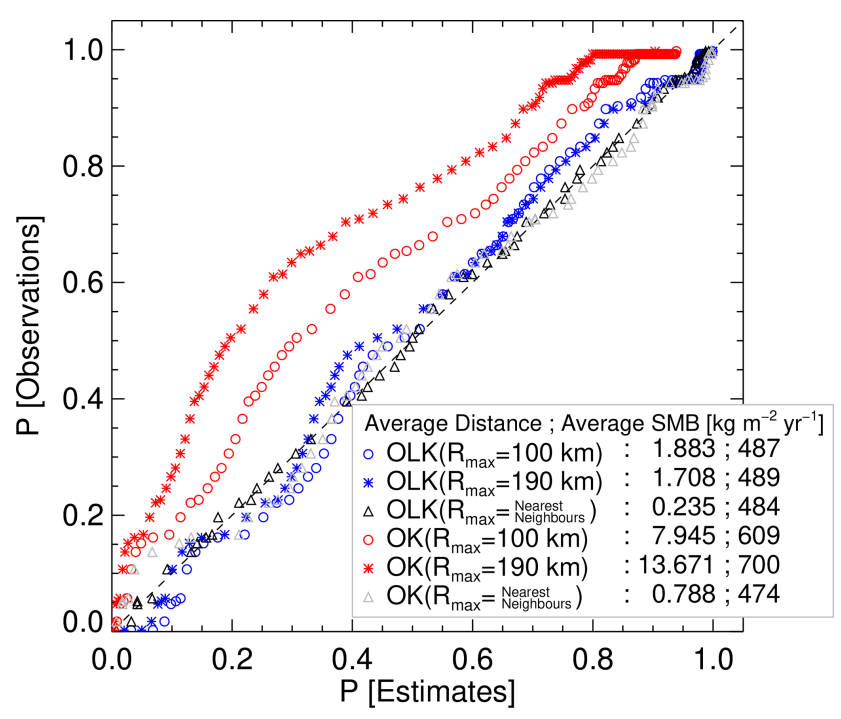

Figure 7. PP plots between SMB observations and estimates based on OK and OLK interpolation methods for varying thresholds of their maximum distance $R_{\max }$. The dashed $1: 1$ line indicates the complete PP agreement between observations and estimates. Average PP distances (see main text for definition) and SMB values are shown in the legend.

of transformed SMB observations, the estimates must be transformed back into the original measurement scale. This back transformation requires the addition of a correction term for each OK estimate to ensure that the expected value is equal to the sample mean and that the smoothing effect is 
adequately compensated (i.e. resulting estimates reproduce the sample histogram and sample mean; Yamamoto, 2007). We implemented such an ordinary logarithmic kriging (OLK) method in our analysis by adopting the fourstep post-processing algorithm proposed by Yamamoto (2007) for the estimation of "nonbias terms". According to Yamamoto (2008), OLK does not necessarily require a lognormal sample distribution to produce improved estimates in terms of local accuracy. Furthermore, Yamamoto (2007) tested the impact of constant $C$ according to Eq. (6) and found that a data translation towards higher values yields an approximation from OLK to OK estimates, thus eliminating the advantage of improved sample mean reproduction and local accuracy of OLK estimates. Indeed, we find that adding a negative constant $C$ to all SMB values, such that the lowest SMB value reaches $0.1 \mathrm{~kg} \mathrm{~m}^{-2} \mathrm{yr}^{-1}$, yields an improved reproduction of the observation data characteristics. Figure 6 shows the experimental isotropic semivariogram of our log-transformed SMB observations from Fig. 5b together with a Gaussian model fit with a practical range of $\sim 190 \mathrm{~km}$, i.e. the range at which the spatial autocorrelation of sample points is vanishing. Following Yamamoto $(2005,2007)$, we investigate the reproduction of observational data characteristics by means of PP plots (i.e. percentiles of cumulative distributions of observations and estimates against each other). Figure 7 shows the PP plots for our OLK and OK interpolation constrained to a maximum estimation range threshold $R_{\max }$ with regard to the closest ASIRAS measurement locations of 100 and $190 \mathrm{~km}$ and nearest-neighbour locations. By comparison with Fig. 6, the 100 and $190 \mathrm{~km}$ distances (dashed lines) approximately correspond to the lag distances at which the semivariogram has reached half the sill and where it has levelled off, respectively. In addition, the average distance of PP points from the 1:1 line according to the definition in Yamamoto (2005) and the average SMB values for the OK and OLK estimates are shown in the legend. Both the nearest-neighbour OK and OLK average SMB estimates are close to the average SMB observation value of $474 \mathrm{~kg} \mathrm{~m}^{-2} \mathrm{yr}^{-1}$. However, after increasing the range threshold $R_{\max }$ to 100 and $190 \mathrm{~km}$, it is evident from Fig. 7 that the best match exists between the observation and OLK estimation values. Hence, we limit our analysis to these values in the following.

Aside from the choice of the translational constant $C$ and semivariogram model, we choose the method proposed by Deutsch (1996) to correct for negative kriging weights (Yamamoto, 2000) and constrain all processing steps of the OLK estimation to the 16 nearest neighbours for each estimate according to the quadrant criterion. Depending on the neighbourhood considered, the effect of smoothing as well as local stationarity of observation data is affected. As a guidance for our final setting, we aimed at generating an optimal PP relation according to Fig. 7 but also considered potential artefacts which may arise from the OLK procedure.
In addition to each OLK estimate, we calculate the associated interpolation error. While ME14 choose the kriging standard deviation as a measure of interpolation error, our error estimation is based on the interpolation standard deviation $S_{0}$ introduced by Yamamoto (2000) for two reasons. Firstly, as shown by the author, $S_{0}$ represents a more complete measure of local accuracy and has, therefore, been implemented in the post-processing algorithm in Yamamoto (2007). Secondly, for the OLK method we need a corresponding back transformation of the interpolation error from the logarithmic to the measurement scale, which has been investigated for $S_{0}$ in Yamamoto (2008). Thus, we adopted the proposed back transformation of $S_{0}$ in this study.

Following ME14, we estimate the total error of each SMB estimate by the RSS of the measurement error and back-transformed $S_{0}$. The measurement error is estimated by generating 500 realizations of OLK SMB estimates with added noise to the smoothed SMB observations, which follows a normal distribution with a mean of zero and standard deviation equal to the measurement error of the SMB observation at $x_{0}$.

We have to keep in mind that the basin-wide SMB OLK estimation is limited in terms of the practical range according to Fig. 6. By comparison with the flight track shown in Fig. 1, even when considering the practical range as a maximum threshold for the spatial SMB estimation, we do not cover the entire PIG basin (see Fig. 8). Hence, for the calculation of total mass input to the PIG basin, we replace SMB OLK estimates with modelled SMB from a regional climate model at distances where the spatial autocorrelation of measurements is low. In the next section, we consider SMB estimates from the RACMO2.3p2 (van Wessem et al., 2018) regional climate model (in the following abbreviated as RACMO) and the Modèle Atmosphéric Régional (MAR) according to Donat-Magnin et al. (2020).

\section{Results}

\subsection{Regional-scale SMB distribution}

Based on the adopted OLK interpolation scheme, we produced the mean annual SMB map for the PIG basin from the ASIRAS observations in Fig. 8a. SMB observations and estimates are colour coded with the same scale. Each estimate covers a pixel size of $\sim 5$ by $5 \mathrm{~km}^{2}$ and refers to the averaging period between November 2004 and December 2014. The two surrounding dashed lines indicate the 100 and $190 \mathrm{~km}$ maximum distances from the ASIRAS measurement point cloud discussed earlier. The red triangle denotes an artificial interpolation cluster of 8 pixels with SMB values greater than $2000 \mathrm{~kg} \mathrm{~m}^{-2} \mathrm{yr}^{-1}$, which we discuss in Sect. 4.4. Furthermore, some streak artefacts are visible from the interpolation, which are mainly caused by 

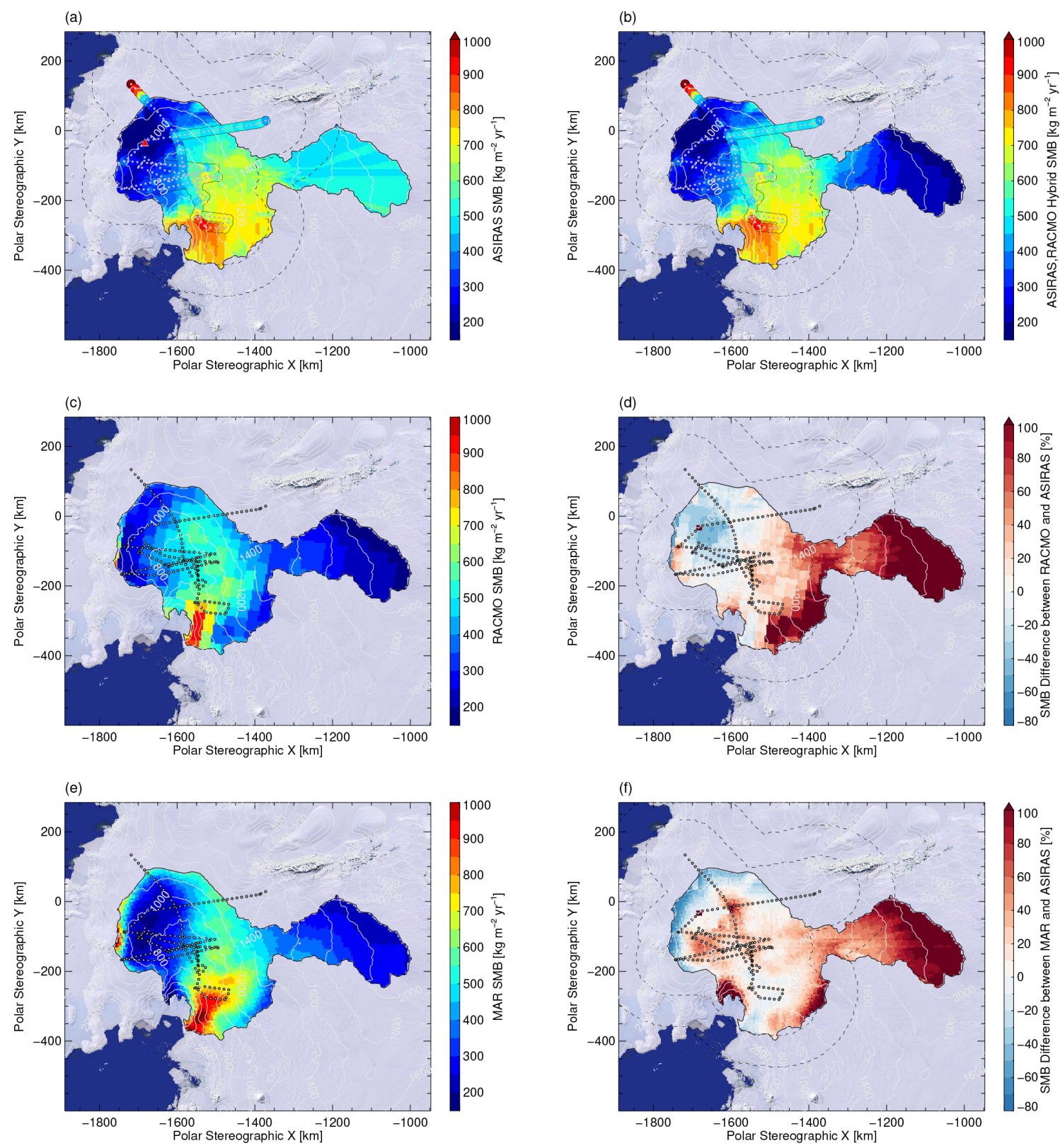

Figure 8. (a) ASIRAS annual mean SMB OLK estimates between November 2004 and December 2014. Measurement points colour coded with the same SMB scale. Red triangle denotes the position of an interpolation artefact (see Sect. 4.5). (b) Hybrid SMB map with ASIRAS estimates (a) linearly relaxing into RACMO SMB estimates (c), which have been extracted for the same averaging period. Dashed lines denote the 100 and $190 \mathrm{~km}$ maximum distance to the ASIRAS estimates and confine the transition zone between ASIRAS- and model-based SMB estimates (a, b, d, f). (d) Relative SMB change from RACMO to ASIRAS, i.e. [(a) - (c)]/(c) $\times 100$. (e, f) MAR SMB fields and relative difference to ASIRAS by analogy with panel (d). Background imagery taken from U.S. Geological Survey (2007) for all panels.

the quadrant criterion of the OLK estimation. Increasing the number of nearest neighbours helps reduce these artefacts but at the cost of PP agreement in terms of Fig. 7. We therefore kept the OLK settings according to Fig. 8a hereinafter.

Figure $8 \mathrm{c}$ and $\mathrm{d}$ show mean annual SMB estimates for the same period based on RACMO and MAR simulations, respectively. The horizontal resolution of simulated SMB is $27 \mathrm{~km}$ for RACMO and $10 \mathrm{~km}$ for MAR runs. ASIRAS- and model-based estimates show similar main characteristics, i.e. increasing SMB rates towards the Amundsen Sea coastline, decreasing SMB rates towards the inland, and a region of low SMB in response to the shadowing effect from the mountain ranges of Eights Coast. Similar characteristics also exist for the SMB map generated by M14. Furthermore, the ASIRAS observations start to capture the transition to higher snow accumulation at the ice divide 
along the Eights Coast mountain range, as indicated by both regional climate models. This is best seen in the highresolution observations north of iSTAR site 10 according to Fig. 5.

Figure $8 \mathrm{~d}$ and $\mathrm{f}$ show the relative difference between model and ASIRAS SMB estimates as defined in the caption. Local variations can be found in the agreement between ASIRAS- and model-based estimates. Among others, the shadowing effect appears to be more pronounced in the MAR and ASIRAS estimates than in the RACMO estimates. Furthermore, the MAR estimates tend to be lower at the central flight lines compared to the RACMO and ASIRAS estimates, whereas the agreement is the best between the MAR and ASIRAS estimates near coastal iSTAR sites. A common feature of the ASIRAS estimates is the much less pronounced SMB gradient towards the southern interior compared to both model estimates but also to the M14 estimates. This can be explained by the missing observational constraints in this region. We therefore generated hybrid SMB maps where ASIRAS estimates linearly relax into either MAR or RACMO estimates between the 100 to $190 \mathrm{~km}$ range interval (dashed lines), as shown in Fig. 8b for complementary ASIRAS-RACMO estimates. The range interval was selected based on the spatial autocorrelation in terms of Fig. 6. It is evident from Fig. 8d and $\mathrm{f}$ that the SMB gradient towards the southern interior is not the same for the MAR and RACMO simulations. Hence, the selection of complementary model data will impact total mass input estimates for the PIG basin.

\subsection{Total mass input}

Spatial integration of annual mean SMB from our generated hybrid maps yields the total mass input for the PIG basin, which we denote by $\Sigma_{+}$. Table 3 summarizes $\Sigma_{+}$and further statistical SMB characteristics for different data sets and basin definitions according to Fig. 9d. Here, we replaced the interpolation artefact highlighted in Fig. 8a with averaged values from neighbouring pixels. $\Sigma_{+}$uncertainty estimates refer to the RSS of the interpolation and measurement error grids (Fig. 9c) in accordance with ME14. Because of a missing error grid for simulated SMB, we consider the total combined error for the entire PIG basin a conservative error estimate. In this sense, we are augmenting the missing model error estimation. To quantify the relative contribution of ASIRAS to the hybrid SMB estimates, OLK area and OLK $\Sigma_{+}$denote the relative contribution in terms of covered land area and integrated SMB, respectively. For comparison with the hybrid-based estimates of this study, we include results from RACMO, MAR, and ME14, which we converted from w.e. depth to SI units. Because of the different averaging periods between this study and ME14, we added model estimates in brackets, which we extracted based on the same averaging period as for the ME14 results.

\subsubsection{Pine Island and Wedge zone}

The Pine Island $\Sigma_{+}$values are in agreement between all data sets within the estimated error margins. This is different for the Wedge area, where the RACMO $\Sigma_{+}$estimates are between $35 \%-40 \%$ lower compared to the estimates of this study and ME14. Increasing the averaging time of RACMO estimates to the 1985-2009/2010 period of the ME14 results yields an increase in $\Sigma_{+}$by $2 \%$ for the Pine Island and $8 \%$ for the Wedge area. However, the RACMObased total mass input to the Wedge area remains below the observational error margins. In comparison with RACMO and MAR estimates, we find that MAR-based $\Sigma_{+}$values are about 5\% higher for Pine Island and 38\% higher for the Wedge area. The higher MAR SMB compared to RACMO towards the southern interior yields a $3 \%$ increase for hybrid SMB estimates based on complementary MAR estimates. Considering the additional SMB properties according to Table 3, the hybrid-based SMB estimates of this study show the largest variability, except for the Wedge area.

\subsubsection{Additional basin definitions}

Table 3 includes results based on two additional basin definitions for PIG. Figure 9d shows a composite plot of all basin definitions used here. The surface areas range between $176.5,178.6$, and $208.8 \times 10^{3} \mathrm{~km}^{2}$ for the PIG basin (including Wedge) according to the definitions of Mouginot et al. (2017), Fretwell et al. (2013), and Zwally et al. (2012). With regard to the basin definition according to Mouginot et al. (2017), $\Sigma_{+}$increases by about $3 \%$ for the definition by Fretwell et al. (2013) and between $15 \%$ to $19 \%$ for the definition by Zwally et al. (2012), depending on which data set is considered according to Table 3 .

\section{Discussion}

We discuss first the pronounced differences between annual layer dating from ASIRAS reflection and neutron probe density profiles at some sites and then secondly the systematic differences in SMB distribution between the results of this study and those of ME14, RACMO, and MAR.

\subsection{Local SMB departures}

Key to the evaluation of our selected internal reflection layer is its isochronic nature, which we assume based on matched depth-age relations from the iSTAR ground-truthing measurements. One may argue that these measurements can be subject to local noise in the density profile, which would challenge any comparison with nearby radar observations. For instance, Laepple et al. (2016) observed dominating stratigraphic noise at single pit density profiles near Kohnen station (East Antarctic plateau, Dronning Maud Land). Stacking of multiple profiles is one possibility to 
Table 3. Spatially integrated SMB $\left(\Sigma_{+}\right)$, mean $\left(\mu_{\dot{b}}\right)$, standard deviation $\left(\sigma_{\dot{b}}\right)$, minimum, and maximum SMB based on different data sets and basin definitions according to Fig. 9d. For the hybrid SMB estimates of this study, the areal contribution as well as the contribution of spatially integrated SMB from the ASIRAS estimates is denoted by OLK area and OLK $\Sigma_{+}$, respectively. In addition to the November 2004 to December 2014 averaging period of the hybrid estimates, RACMO and MAR estimates separated by semicolon refer to the July 1985 to January 2010 averaging period in accordance with the results from M14.

\begin{tabular}{|c|c|c|c|c|c|c|c|c|}
\hline \multirow[b]{2}{*}{ Data set } & \multirow[b]{2}{*}{ Basin } & \multirow{2}{*}{$\frac{\mathrm{Gtyr}^{-1}}{\Sigma_{+}}$} & \multicolumn{4}{|c|}{$\mathrm{kg} \mathrm{m}^{-2} \mathrm{yr}^{-1}$} & \multicolumn{2}{|c|}{$\%$} \\
\hline & & & $\mu_{\dot{b}}$ & $\sigma_{\dot{b}}$ & $\min$ & $\max$ & OLK area & OLK $\Sigma_{+}$ \\
\hline \multirow{5}{*}{$\begin{array}{l}\text { Hybrid } \\
\text { ASIRAS, RACMO }\end{array}$} & Pine Island & $69.0 \pm 17.6$ & 421 & 195 & 147 & 958 & 72.1 & 82.9 \\
\hline & Wedge & $10.9 \pm 1.6$ & 729 & 48 & 591 & 847 & 99.5 & 99.6 \\
\hline & Pine Island and Wedge & $79.9 \pm 19.2$ & 447 & 206 & 147 & 958 & 74.4 & 85.2 \\
\hline & PIG (Mouginot et al., 2017) & $77.5 \pm 19.2$ & 439 & 198 & 132 & 958 & 75.3 & 85.1 \\
\hline & PIG (Zwally et al., 2012) & $92.4 \pm 22.4$ & 443 & 195 & 79 & 958 & 74.6 & 84.0 \\
\hline \multirow{5}{*}{$\begin{array}{l}\text { Hybrid } \\
\text { ASIRAS, MAR }\end{array}$} & Pine Island & $71.2 \pm 17.6$ & 434 & 185 & 188 & 958 & 72.1 & 80.5 \\
\hline & Wedge & $10.9 \pm 1.6$ & 729 & 48 & 599 & 847 & 99.5 & 99.6 \\
\hline & Pine Island and Wedge & $82.1 \pm 19.2$ & 459 & 195 & 188 & 958 & 74.4 & 83.1 \\
\hline & PIG (Mouginot et al., 2017) & $79.5 \pm 19.2$ & 451 & 188 & 188 & 958 & 75.3 & 83.2 \\
\hline & PIG (Zwally et al., 2012) & $94.7 \pm 22.4$ & 455 & 188 & 0 & 1258 & 74.6 & 81.9 \\
\hline \multirow{5}{*}{$\begin{array}{l}\text { RACMO } \\
\text { (Nov 2004-Dec 2014; } \\
\text { Jul 1985-Jan 2010) }\end{array}$} & Pine Island & $64.7 ; 65.8$ & $395 ; 401$ & $147 ; 152$ & $147 ; 144$ & $935 ; 989$ & & \\
\hline & Wedge & $6.6 ; 7.1$ & $439 ; 476$ & $180 ; 189$ & $287 ; 315$ & $935 ; 989$ & & \\
\hline & Pine Island and Wedge & $71.2 ; 72.9$ & $398 ; 408$ & $151 ; 157$ & $147 ; 144$ & $935 ; 989$ & & \\
\hline & PIG (Mouginot et al., 2017) & $70.6 ; 72.1$ & $400 ; 409$ & $150 ; 157$ & $132 ; 131$ & $935 ; 989$ & & \\
\hline & PIG (Zwally et al., 2012) & $81.6 ; 83.6$ & $392 ; 401$ & $151 ; 158$ & $0 ; 0$ & $935 ; 1005$ & & \\
\hline \multirow{5}{*}{$\begin{array}{l}\text { MAR } \\
\text { (Nov 2004-Dec 2014; } \\
\text { Jul 1985-Jan 2010) }\end{array}$} & Pine Island & $67.7 ; 69.2$ & $413 ; 422$ & $173 ; 176$ & $86 ; 126$ & $1176 ; 1162$ & & \\
\hline & Wedge & $9.1 ; 9.3$ & $607 ; 622$ & $195 ; 201$ & $336 ; 350$ & $1131 ; 1162$ & & \\
\hline & Pine Island and Wedge & $76.8 ; 78.5$ & $430 ; 439$ & $183 ; 186$ & $86 ; 126$ & $1176 ; 1162$ & & \\
\hline & PIG (Mouginot et al., 2017) & $74.4 ; 76.1$ & $422 ; 431$ & $184 ; 187$ & $16 ; 48$ & $1176 ; 1162$ & & \\
\hline & PIG (Zwally et al., 2012) & $87.0 ; 89.1$ & $417 ; 428$ & $187 ; 189$ & $-53 ;-36$ & $1802 ; 1771$ & & \\
\hline \multirow[t]{2}{*}{ M14 } & Pine Island & $67.3 \pm 6.1$ & 400 & 130 & 210 & 840 & & \\
\hline & Wedge & $11.0 \pm 0.7$ & 590 & 160 & 160 & 330 & & \\
\hline
\end{tabular}

filter out noise. While this is not possible for the single iSTAR sites, the estimated dating uncertainty of \pm 1.4 years according to this study suggests that iSTAR ground-truthing measurements at PIG are less prone to stratigraphic noise, which is most likely to be related to the higher SMB compared to $\sim 70 \mathrm{~kg} \mathrm{~m}^{-2} \mathrm{yr}^{-1}$ near Kohnen station (Laepple et al., 2016). However, on a few occasions we identified larger departures in the annual layer dating, as is the case for iSTAR site 2 (Table 2). While the layer tracing appears to be in agreement between site 1 and 3, the annual layer dating at site 2 would suggest an SMB of $\sim 290 \mathrm{~kg} \mathrm{~m}^{-2} \mathrm{yr}^{-1}$ at the traced layer cross section rather than $\sim 150 \mathrm{~kg} \mathrm{~m}^{-2} \mathrm{yr}^{-1}$ based on the 2004.8 layer dating of this study. Accordingly, local SMB results would increase by $\sim 100 \%$ if we used the uncorrected depth-age scale at site 2 , which most likely indicates a systematic error in the measurement scale. This is further corroborated by the measured SMB of $140 \mathrm{~kg} \mathrm{~m}^{-2} \mathrm{yr}^{-1}$ at site 2 for the most recent 2014 layer, but also measured density and strain-rate profiles suggest a mean annual SMB of $200 \mathrm{~kg} \mathrm{~m}^{-2} \mathrm{yr}^{-1}$ based on the Herron and Langway (1980) stage 1 equation; both observations are in a better agreement with the collocated ASIRAS-based results than the SMB estimate based on the annual layer dating from the NP measurements at site 2. In this sense, the ASIRAS results allow us to be more confident of the site 2 strain-rate measurements and therefore add to the densification analysis of Morris et al. (2017). The local SMB estimates near site 2 from ME14 and RACMO are within the 200 to $300 \mathrm{~kg} \mathrm{~m}^{-2} \mathrm{yr}^{-1}$ range but lack the local precision of ASIRAS measurements and therefore could not explain the measured density and strain-rate profiles at site 2 . The bias to the ASIRAS observations also exists for the MAR estimates, which reach the $350 \mathrm{~kg} \mathrm{~m}^{-2} \mathrm{yr}^{-1}$ level near site 2 but experience a strong gradient along the PIG main trunk.

Nearby ASIRAS observations at site 18 and 19 in particular suggest higher SMB values compared to the dated NP profiles. Site 19 is directly located at the centre of a pronounced accumulation trough of $\sim 2.5 \mathrm{~km}$ width, which adds to the uncertainty in the layer matching because of the spatial displacement between the iSTAR site and point of closest approach. Because the traced reflection layer significantly exceeds the depth range of the dated NP density profiles at site 18 and 19, we discarded both sites for the layer dating.

Additional local departures between our results and those from ME14 were identified for the northern slopes and southward interior of PIG. Because of difficulties in the layer tracing at the northern slopes, the authors of M14 had to 
augment their SMB estimates with results from a different layer, which they dated back to 2002 and corrected for a temporal bias to the 1985 layer based on overlapping segments. Thus, one possible explanation for the observed differences is that the true local temporal bias correction may be different from the regional-scale bias correction, which they estimate from regression models. Other possible explanations are differences in the observational coverage and local accuracy from the different interpolation methods. With regard to the southward interior, the spatial coverage is superior in the ME14 results. Despite the maximum range limit between 100 and $190 \mathrm{~km}$ for the ASIRAS-based estimates, the missing observational constraints towards the interior may still yield an underestimation of the southward SMB gradient. However, we also cannot rule out that the smaller gradient in our observations is due to a local increase in SMB between the different observational periods in both studies. Additional observational constraints of the selected reflection layer may resolve the cause for the observed difference.

\subsection{Elevation-dependent model drift}

The observational SMB estimates by M14 indicate an elevation-dependent drift of simulated SMB from RACMO. The authors find that RACMO underestimates the SMB at the high-elevation interior, which would also impact our ASIRAS-RACMO-based estimates of total mass input. Indeed, this finding is also reflected in our data (see Supplement S1) and suggests that the ASIRASRACMO-based total mass input estimates are biased by the underestimated SMB contribution from RACMO. According to Agosta et al. (2019), the opposite may apply for the ASIRAS-MAR-based estimates. The authors observe a tendency for MAR to overestimate accumulation on Marie Byrd Land (Ross Ice Shelf) and conclude that differences between MAR and RACMO2 are very likely related to differences in the advection inland. Similar to our elevationdependent comparison between ASIRAS and RACMO SMB estimates, we find evidence of a drift in the MAR estimates with an opposite sign according to Supplement S1. We conclude that the best estimate for total mass input lies between ASIRAS-RACMO and ASIRAS-MAR estimates.

\subsection{Impact on recent mass balance estimates}

Despite the local differences in the SMB distribution, the difference between the $\Sigma_{+}$estimates for the PIG catchment (including Wedge) between this study and ME14 is small; i.e. the ASIRAS-RACMO hybrid $\Sigma_{+}$is $1.7 \mathrm{Gtyr}^{-1}$ larger, which corresponds to $2 \%$ of the ME14 value. Similarly, the ASIRAS-MAR hybrid estimates are 5\% larger compared to ME14, which is still within the uncertainty range estimated by the authors of M14. This indicates that the local differences in the SMB estimates between both studies cancel out. If we take into account that the temporal averaging time used by ME14 is about a factor of 2.7 larger than that used in this study, we cannot find evidence of a potential secular trend in SMB at decadal scales similar to that of the ice discharge at PIG. This provides additional evidence to Medley et al. (2013) that the recent temporal evolution of the PIG mass balance is primarily driven by dynamic ice loss into the Amundsen Sea.

With regard to existing mass balance estimates for PIG, we have to take into account that basin outlines can differ significantly between studies as illustrated in Fig. 9d. To evaluate the impact of our hybrid SMB estimates on recent mass balance inventories, we extracted results from the literature in Table 4 and added updated mass balance estimates $\Sigma_{+}^{-}$by replacing the $\Sigma_{+}$estimates from the literature with the $\Sigma_{+}$estimates of this study. We assume that the SMB remains stationary for the mass balance calculation with regard to the shown periods. In addition, we linearly interpolated the estimated ice discharge measurements in ME14 for the missing periods before 2007. Furthermore, we assume that the unspecified basin definitions in ME14 are in close agreement with the basin definitions based on Fretwell et al. (2013).

The small difference between the $\Sigma_{+}$estimates of this study and ME14 directly translates into the $\Sigma_{+}^{-}$mass balance estimates. The largest impact of our results is on the $\Sigma_{+}^{-}$ estimate by Gardner et al. (2018). After replacing their $\Sigma_{+}$ estimate from RACMO2.3 simulations with our ASIRASMAR hybrid $\Sigma_{+}$estimate, the mass balance increases by $\sim 11 \mathrm{Gtyr}^{-1}$.

\subsection{SMB uncertainty}

While the agreement in $\Sigma_{+}$estimates between this study and ME14 supports the hypothesis that the regional SMB of PIG is stationary at decadal scales, our uncertainty estimates are much larger. The temporal error according to Fig. 4, which is $\sim 5 \%$ larger than in Medley et al. (2013) and ME14, cannot fully explain the difference between both uncertainty estimates. We also do not expect any major differences with regard to the spatial uncertainty of the density profiles. According to the error-grid statistics of the ASIRAS-RACMO-based estimates in Table 5, we identify the back-transformed interpolation standard deviation $S_{0}$ from the OLK scheme as the dominating error source of our results, while the combined error in ME14 is slightly above our measurement error. The dominating $S_{0}$ uncertainty is also evident in Fig. 9a, b, and c, where the spatial features of the combined error grid are predominately determined by the $S_{0}$ grid. We find that the low accumulation zone at the northern slopes of PIG, which is next to the main trunk between iSTAR site 1 to 6 , shows combined $S_{0}$ patches that considerably exceed $100 \%$. In contrast, combined error estimates in ME14 do not exceed $20 \%$ at the same location. 
Table 4. Updated mass balance estimates $\Sigma_{+}^{-}$for different studies based on hybrid $\Sigma_{+}$estimates of this study using complementary (RACMO; MAR) SMB estimates. Indicated periods refer to the considered ice loss processes. Net gain from $\Sigma_{+}$is assumed to be stationary during the indicated periods.

\begin{tabular}{lllrr}
\hline Study & Period & Basin definition & $\Sigma_{+}^{-}\left(\mathrm{Gtyr}^{-1}\right)$ & $\begin{array}{r}\text { Updated } \Sigma_{+}^{-}\left(\mathrm{Gt} \mathrm{yr}^{-1}\right) \\
\text { (RACMO; MAR) hybrid }\end{array}$ \\
\hline M14 & 2005-2012 & Pine Island (M14) & $-41 \pm 7$ & $-(39 ; 37) \pm 18$ \\
M14 & $2005-2010$ & Wedge (M14) & $-0.6 \pm 2.5$ & $-(0.7 ; 0.7) \pm 3.1$ \\
Gardner et al. (2018) & $2008-2015$ & Zwally et al. (2012) & $-49 \pm 19$ & $-(40 ; 38) \pm 28$ \\
Rignot et al. (2019) & 2005-2014 & Mouginot et al. (2017) & $-51 \pm 7$ & $-(46 ; 44) \pm 20$ \\
\hline
\end{tabular}

Table 5. Mean $\left(\mu_{\mathrm{err}}\right)$, standard deviation $\left(\sigma_{\mathrm{err}}\right)$, minimum, and maximum gridded SMB errors with respect to basin-wide hybrid ASIRASRACMO SMB estimates. Mean and $\sigma$ values in brackets are limited to the $190 \mathrm{~km}$ practical range threshold and weighted according to the ASIRAS partitioning in Fig. 8b.

\begin{tabular}{lrrrr|rrrr}
\hline & \multicolumn{3}{c}{ Pine Island } & \multicolumn{4}{c}{ Wedge } \\
\cline { 2 - 8 }$\%$ & $\mu_{\text {err }}$ & $\sigma_{\text {err }}$ & $\min$ & $\max$ & $\mu_{\text {err }}$ & $\sigma_{\text {err }}$ & min & $\max$ \\
\hline Measurement error & $9.9(7.2)$ & $5.2(1.8)$ & 3.7 & 40.5 & 7.2 & 0.9 & 5.8 & 9.5 \\
$S_{0}$ & $32.2(25.5)$ & $32.7(34.9)$ & 0.5 & 481.8 & 12.5 & 11.3 & 2.1 & 57.3 \\
Combined Error & $34.4(27.4)$ & $32.4(34.2)$ & 6 & 481.9 & 15.2 & 10.2 & 7.3 & 57.8 \\
Medley et al. (2014) & 10.4 & 6.1 & 2.6 & 30.0 & 6.3 & 1.8 & 2.9 & 10.8 \\
\hline
\end{tabular}

Initial tests on our OLK setting revealed that the choice of the negative kriging weight correction method has a noticeable impact on the uncertainty estimates, a finding which according to our knowledge has not been reported before. However, our applied method by Deutsch (1996) already yields the minimum uncertainty estimates for our results, whereas the additional methods cited in Yamamoto (2000) yields an additional uncertainty increase between $20 \%$ (Froidevaux, 1993) and 50\% (Journel and Rao, 1996).

Additional tests, where we used the kriging standard deviation based on non-transformed OK estimates, did not improve our interpolation uncertainty. Therefore the different choice of the interpolation uncertainty measure is not the source of the larger uncertainty range of this study. We hypothesize that despite the homoscedastic (i.e. data-valueindependent) nature of the krige standard deviation, the reduction of data variance after subtracting the regression surface according to ME14 is most likely the cause of their significantly lower uncertainty estimates.

In addition to the larger uncertainty range of this study, we note that the choice between cell-by-cell summation and RSS of grid errors has a quite substantial impact on the $\Sigma_{+}$uncertainty estimates. If we make the optimistic assumption that gridded errors are independent and choose the calculation of RSS instead, $\Sigma_{+}$uncertainty estimates would reduce to $\pm 0.5 \mathrm{Gtyr}^{-1}$ (i.e. $\sim 97 \%$ less) for the combined Pine Island and Wedge basin.

\subsection{Systematic retrieval impacts}

In addition to the uncertainty assessment in Sect. 4.4, we evaluated the impact of artificial cluster removal, the choice of permittivity model, and the non-transformed OK scheme.

\subsubsection{Artificial cluster removal}

Inspection of the artificial cluster highlighted in Fig. 8 revealed that it is centred around the location with the lowest observed SMB and is essentially generated by the local nonbias terms of the OLK procedure. Owing to its steep contrast with the surroundings, it appears to be plausible to replace this cluster by averaged values of its nearest neighbours. However, due to the limited extent of this cluster, its additional contribution to the $\Sigma_{+}$estimates would be less than $0.8 \%$. Similarly, the impact on the PP plot is negligible. Increasing the translational constant $C$ helps remove this cluster but at the cost of statistical agreement between observations and estimates.

\subsubsection{Looyenga-based results}

Defining $\epsilon^{\prime}$ by Eq. (2) instead of Eq. (1) yields a minor reduction of $\Sigma_{+}$for the PIG catchment of $0.6 \%$, which we expect from Sinisalo et al. (2013). However, despite the minor impact of the alternative definition for $\epsilon^{\prime}$, we noticed an additional small impact on the layer dating, which shifted our estimated layer formation from November to September 2004. Thus, we had to adjust the time range in the RACMO SMB extraction for the calculation of hybrid 
(a)

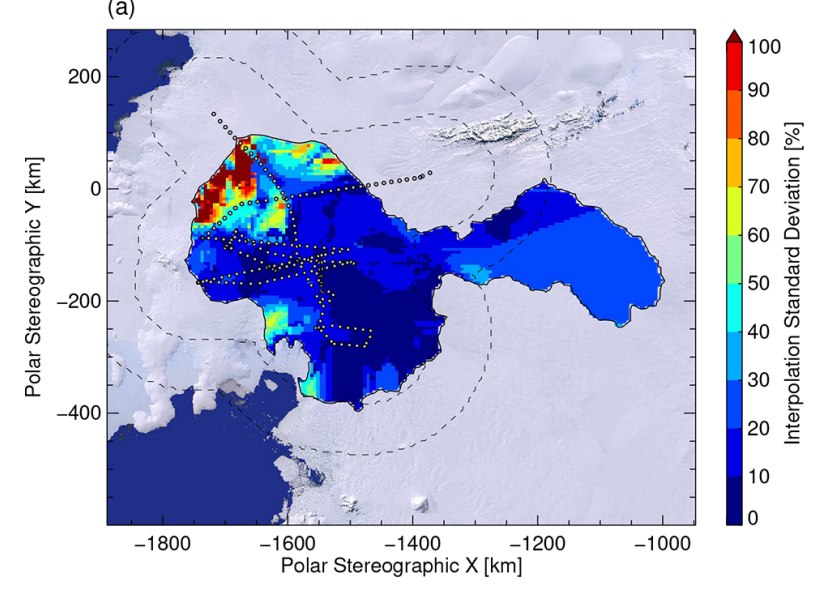

(c)

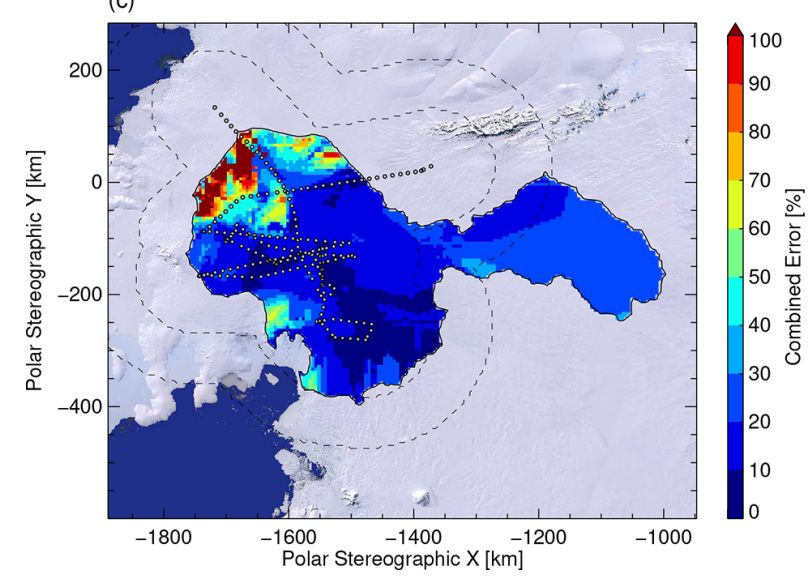

(b)

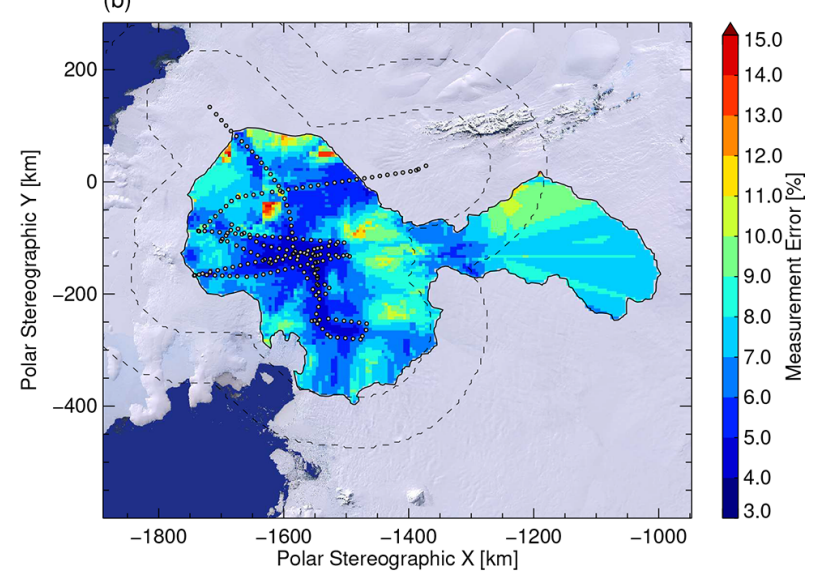

(d)

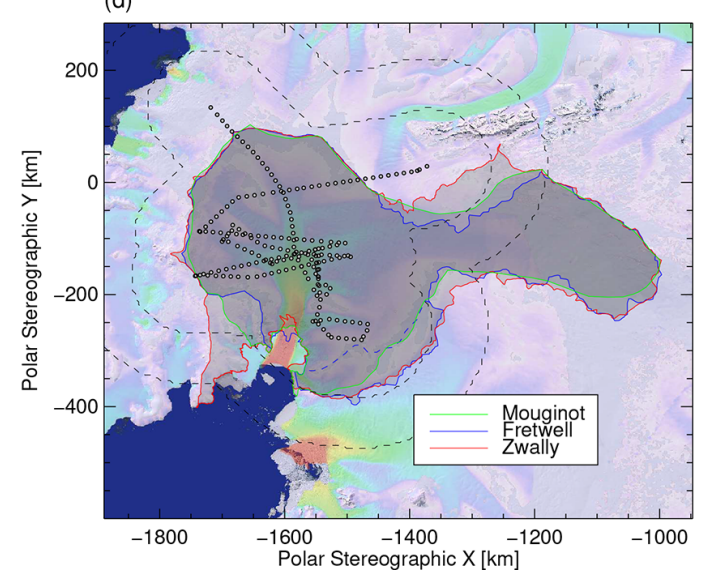

Figure 9. (a, b) Interpolation standard deviation $S_{0}$ and measurement error of Fig. 8a. (c) Root sum of squares of panels (a) and (b). (d) Varying PIG basin definitions according to Zwally et al. (2012), Fretwell et al. (2013), and Mouginot et al. (2017). Surface flow speeds adopted from Fig. 1. Background imagery taken from U.S. Geological Survey (2007) for all panels.

SMB estimates. While the choice of the $\epsilon^{\prime}$ model only has a minor impact on our total mass input estimates, it is worth noting that the effect on our annual layer dating is detectable.

\subsubsection{Non-transformed kriging results}

If we choose the OK procedure instead, $\Sigma_{+}$increases by $4 \%$ for the Pine Island and $12 \%$ for the Wedge area, which would further increase the offset between this study and ME14. However, inspection of the SMB distribution (not shown) indicates that estimates tend to overshoot near the coastline of the Amundsen Sea, which becomes particularly evident for the Wedge area. Hence, the OK procedure appears to be more sensitive to the limited observational constraints near the Wedge area. In addition, $S_{0}$-based uncertainty estimates increase by $27 \%$ and $88 \%$ for the Pine Island and Wedge area, which highlights the improved performance of the OLK procedure.

\section{Conclusions}

Our analysis provides updated mean annual SMB estimates for the PIG basin and 2005-2014 averaging period based on a comprehensive airborne radar and ground-truthing survey and complementary model simulations. Based on these estimates, we calculated a total mass input of $79.9 \pm$ 19.2 and $82.1 \pm 19.2 \mathrm{Gtyr}^{-1}$ for the PIG basin area when using complementary RACMO and MAR SMB estimates, respectively. In comparison with earlier estimates from airborne radar observations, which consider the 1985-2009 averaging period, our results show a greater total mass input between $2 \%$ and $5 \%$. This increase is still within the uncertainty range of both studies. Hence, no distinct trend is visible for the total mass input between both averaging periods. We conclude that our results provide further evidence that the recent total mass input can be considered stationary at decadal scales. This implies that the increased dynamic ice loss over past decades remains the driving force in the recent mass balance evolution of PIG. However, 
departures between both observations at the northern slopes and southward interior of PIG, which cancel out for the estimates on total mass input, may indicate temporal changes in the local SMB distribution. Furthermore, our radar-based observations can resolve a discrepancy between strain-rate and SMB measurements at iSTAR site 2, which highlights the benefit of such complementary SMB measurements for future missions.

Despite the minor changes in total mass input between both studies, the more than 2-fold uncertainty range of our results remains striking. Neither the applied model for the wave propagation speed of radar soundings nor the uncertainty related to the regional density profile can explain the larger uncertainty of this study. The same also applies for the reduced temporal averaging time. A comprehensive evaluation of our uncertainty estimation revealed that assumptions on the geostatistical interpolation error as well as grid-error dependences can have a substantial impact on the uncertainty estimation. In terms of the error partitioning, our interpolation error is the dominating source of combined grid errors. Moreover, varying basin definitions have an impact on our total mass input estimate by up to $19 \%$. This highlights the importance of a thorough documentation of uncertainty estimates and basin definitions to improve future intercomparisons between different SMB and mass balance inventories. 


\section{Appendix A: List of abbreviations and notations}

$\begin{array}{ll}\text { ASIRAS } & \text { Airborne SAR/Interferometric Radar Altimeter System } \\ \text { GPR } & \text { ground-penetrating radar } \\ \text { M14 } & \text { Medley et al. (2014) } \\ \text { Combined error } & \text { root sum of squares of measurement and interpolation standard deviation } \\ \text { Measurement error } & \text { root sum of squares of spatial, temporal, and digitization error components } \\ \text { NP } & \text { neutron probe } \\ \text { OK } & \text { ordinary krige procedure } \\ \text { OLK } & \text { ordinary logarithmic kriging procedure } \\ \text { RACMO } & \text { RACMO2.3p2 regional climate model } \\ \text { PP plot } & \text { percentile-percentile plot } \\ \text { RSS } & \text { root sum of squares } \\ \text { SMB } & \text { surface mass balance, } \mathrm{kg} \mathrm{m}^{-2} \mathrm{yr}^{-1} \\ \text { T1 } & \text { iSTAR traverse 2013/2014 } \\ \text { T2 } & \text { iSTAR traverse 2014/2015 } \\ \text { TWT } & \text { two-way-travel time of radar soundings } \\ \text { PIG } & \text { Pine Island Glacier } \\ \text { w.e. } & \text { water equivalent } \\ \text { WAIS } & \text { West Antarctic Ice Sheet } \\ & \\ a & \text { layer age, years } \\ \dot{b} & \text { annual mean SMB, } \mathrm{kg} \mathrm{m}^{-2} \mathrm{yr}^{-1} \\ \Delta D & \text { closest distance between ASIRAS track and iSTAR site } \\ \epsilon^{\prime} & \text { real part of the dielectric permittivity } \\ N & \text { number of reflection layer points considered for annual dating } \\ \rho & \text { density, kg m }{ }^{-3} \\ R_{\text {max }} & \text { maximum range threshold to ASIRAS measurements, km } \\ \sigma_{x} & \text { standard deviation of } N \text { layer dating estimates } \\ \Sigma_{+} & \text {total mass input, Gtyr } \\ \Sigma_{+}^{-} & \text {total mass balance, } \mathrm{Gt} \mathrm{yr}^{-1} \\ S_{0} & \text { interpolation standard deviation }\end{array}$


Data availability. Underlying data are openly available at Pangaea https://doi.org/10.1594/PANGAEA.927004 (Kowalewski et al., 2021).

Supplement. The supplement related to this article is available online at: https://doi.org/10.5194/tc-15-1285-2021-supplement.

Author contributions. SK conceived of the presented idea, designed the computational framework, adapted and tested the geostatistical krige methods, accomplished the reflection layer tracing in large parts, reprocessed the neutron probe density profiles for the data calibration, and wrote the manuscript with input from all authors; VH performed the SAR level_1b ASIRAS data processing, provided the digital elevation model, and established access to the RACMO2.3p2 data; EM delivered the neutron probe density profiles; and OE contributed to layer analysis and interpretation. All authors discussed the results and contributed to revising the manuscript.

Competing interests. Olaf Eisen is co-editor in chief of The Cryosphere.

Acknowledgements. The authors gratefully acknowledge the excellent logistical support provided by British Antarctic Survey's (BAS) Rothera Research Station and members of the iSTAR traverse and Alfred Wegener Institute and Polar 5 flight crew during the field campaign, which has been funded by the UK Natural Environment Research Council (NERC, grant no. NE/J005681/1). The authors express their gratitude towards Andrew Shepherd, PI of the iSTAR-D project, for his general support and data contribution to this study. The authors thank Robert Mulvaney (BAS, UK) and Hannes Konrad (CPOM, University of Leeds, UK; and DWD, Germany) for provision of data sets and discussions in an early stage. The authors gratefully acknowledge the provision of RACMO2.3p2 model output by Stefan Roderick Martijn Ligtenberg and Melchior van Wessem (IMAU, Utrecht University, NL). The authors would like to thank Emerson E\&P Software, Emerson Automation Solutions, for providing licenses in the scope of the Emerson Academic Program. The authors sincerely appreciate the valuable comments and suggestions by the referees and editor. The authors acknowledge support by the Open Access Publication Funds of Alfred-Wegener-Institut Helmholtz-Zentrum für Polarund Meeresforschung.

Financial support. This research has been supported by the German Ministry of Economics and Technology (grant no. 50EE1331 to Veit Helm).

The article processing charges for this open-access publication were covered by a Research Centre of the Helmholtz Association.
Review statement. This paper was edited by Michiel van den Broeke and reviewed by Brooke Medley and two anonymous referees.

\section{References}

Agosta, C., Amory, C., Kittel, C., Orsi, A., Favier, V., Gallée, H., van den Broeke, M. R., Lenaerts, J. T. M., van Wessem, J. M., van de Berg, W. J., and Fettweis, X.: Estimation of the Antarctic surface mass balance using the regional climate model MAR (1979-2015) and identification of dominant processes, The Cryosphere, 13, 281-296, https://doi.org/10.5194/tc-13281-2019, 2019.

Arcone, S. A., Spikes, V. B., Gordon, S. H., and Mayewski, P. A.: Stratigraphic continuity in $400 \mathrm{MHz}$ short-pulse radar profiles of firn in West Antarctica, Ann. Glaciol., 39, 195-200, https://doi.org/10.3189/172756404781813925, 2004.

Arcone, S. A., Spikes, V. B., and Gordon, S. H.: Phase structure of radar stratigraphic horizons within Antarctic firn, Ann. Glaciol., 41, 10-16, https://doi.org/10.3189/172756405781813267, 2005.

Bamber, J. L. and Dawson, G. J.: Complex evolving patterns of mass loss from Antarctica's largest glacier, Nat. Geosci., 13, 127-131, https://doi.org/10.1038/s41561-019-0527-z, 2020.

Deutsch, C. V.: Correcting for negative weights in ordinary kriging, Comput. Geosci., 22, 765-773, https://doi.org/10.1016/00983004(96)00005-2, 1996.

Donat-Magnin, M., Jourdain, N. C., Gallée, H., Amory, C., Kittel, C., Fettweis, X., Wille, J. D., Favier, V., Drira, A., and Agosta, C.: Interannual variability of summer surface mass balance and surface melting in the Amundsen sector, West Antarctica, The Cryosphere, 14, 229-249, https://doi.org/10.5194/tc-14229-2020, 2020.

Eisen, O., Frezzotti, M., Genthon, C., Isaksson, E., Magand, O., van den Broeke, M. R., Dixon, D. A., Ekaykin, A., Holmlund, P., Kameda, T., Karlöf, L., Kaspari, S., Lipenkov, V. Y., Oerter, H., Takahashi, S., and Vaughan, D. G.: Groundbased measurements of spatial and temporal variability of snow accumulation in East Antarctica, Rev. Geophys., 46, RG2001, https://doi.org/10.1029/2006RG000218, 2008.

Evans, S.: Dielectric Properties of Ice and Snow-a Review, J. Glaciol., 5, 773-792, https://doi.org/10.3189/s0022143000018840, 1965.

Fretwell, P., Pritchard, H. D., Vaughan, D. G., Bamber, J. L., Barrand, N. E., Bell, R., Bianchi, C., Bingham, R. G., Blankenship, D. D., Casassa, G., Catania, G., Callens, D., Conway, H., Cook, A. J., Corr, H. F. J., Damaske, D., Damm, V., Ferraccioli, F., Forsberg, R., Fujita, S., Gim, Y., Gogineni, P., Griggs, J. A., Hindmarsh, R. C. A., Holmlund, P., Holt, J. W., Jacobel, R. W., Jenkins, A., Jokat, W., Jordan, T., King, E. C., Kohler, J., Krabill, W., Riger-Kusk, M., Langley, K. A., Leitchenkov, G., Leuschen, C., Luyendyk, B. P., Matsuoka, K., Mouginot, J., Nitsche, F. O., Nogi, Y., Nost, O. A., Popov, S. V., Rignot, E., Rippin, D. M., Rivera, A., Roberts, J., Ross, N., Siegert, M. J., Smith, A. M., Steinhage, D., Studinger, M., Sun, B., Tinto, B. K., Welch, B. C., Wilson, D., Young, D. A., Xiangbin, C., and Zirizzotti, A.: Bedmap2: improved ice bed, surface and thickness datasets for Antarctica, The Cryosphere, 7, 375-393, https://doi.org/10.5194/tc-7-375-2013, 2013. 
Froidevaux, R.: Constrained kriging as an estimator of local distribution functions, in: Proceedings of the International Workshop on Statistics of Spatial Processes: Theory and Applications, edited by: Capasso, V., Girone, G., and Posa, D., 106-118, Bari, Italia, 1993.

Gardner, A. S., Moholdt, G., Scambos, T., Fahnstock, M., Ligtenberg, S., van den Broeke, M., and Nilsson, J.: Increased West Antarctic and unchanged East Antarctic ice discharge over the last 7 years, The Cryosphere, 12, 521-547, https://doi.org/10.5194/tc-12-521-2018, 2018.

Hawley, R. L., Morris, M. E., Cullen, R., Nixdorf, U., Shepherd, A. P., and Wingham, D. J.: ASIRAS airborne radar resolves internal annual layers in the dry-snow zone of Greenland, Geophys. Res. Lett., 33, L04502, https://doi.org/10.1029/2005GL025147, 2006.

Helm, V., Humbert, A., and Miller, H.: Elevation and elevation change of Greenland and Antarctica derived from CryoSat2, The Cryosphere, 8, 1539-1559, https://doi.org/10.5194/tc-81539-2014, 2014.

Herron, M. M. and Langway, C. C.: Firn Densification: An Empirical Model, J. Glaciol., 25, 373-385, https://doi.org/10.3189/s0022143000015239, 1980.

Hillenbrand, C.-D., Smith, J. A., Hodell, D. A., Greaves, M., Poole, C. R., Kender, S., Williams, M., Andersen, T. J., Jernas, P. E., Elderfield, H., Klages, J. P., Roberts, S. J., Gohl, K., Larter, R. D., and Kuhn, G.: West Antarctic Ice Sheet retreat driven by Holocene warm water incursions, Nature, 547, 43, https://doi.org/10.1038/nature22995, 2017.

Isaaks, E. H. and Srivastava, R. M.: An Introduction to Applied Geostatistic, Comput. Geosci., 17, 471-473, https://doi.org/10.1016/0098-3004(91)90055-I, 1991.

Journel, A. G. and Rao, S. E.: Deriving conditional distributions from ordinary kriging, Tech. Rep. 9, Stanford Center for Reservoir Forecasting, Stanford, 1996.

Konrad, H., Gilbert, L., Cornford, S. L., Payne, A., Hogg, A., Muir, A., and Shepherd, A.: Uneven onset and pace of ice-dynamical imbalance in the Amundsen Sea Embayment, West Antarctica, Geophys. Res. Lett., 44, 910-918, https://doi.org/10.1002/2016gl070733, 2017.

Konrad, H., Hogg, A. E., Mulvaney, R., Arthern, R., Tuckwell, R. J., Medley, B., and Shepherd, A.: Observations of surface mass balance on Pine Island Glacier, West Antarctica, and the effect of strain history in fast-flowing sections, J. Glaciol., 65, 1-10, https://doi.org/10.1017/jog.2019.36, 2019.

Kovacs, A., Gow, A. J., and Morey, R. M.: The in-situ dielectric constant of polar firn revisited, Cold Reg. Sci. Technol., 23, 245256, https://doi.org/10.1016/0165-232X(94)00016-Q, 1995.

Kowalewski, S., Helm, V., Morris, E., and Eisen, O.: Surface mass balance of Pine Island Glacier, West Antarctica over the period 2005-2014, derived from airborne radar soundings and neutron probe measurements, PANGAEA, https://doi.org/10.1594/PANGAEA.927004, 2021.

Laepple, T., Hörhold, M., Münch, T., Freitag, J., Wegner, A., and Kipfstuhl, S.: Layering of surface snow and firn at Kohnen Station, Antarctica: Noise or seasonal signal?, J. Geophys. Res.-Earth Surf., 121, 1849-1860, https://doi.org/10.1002/2016JF003919, 2016.

Lenaerts, J. T. M., van den Broeke, M. R., van de Berg, W. J., van Meijgaard, E., and Kuipers Munneke, P.: A new, high-resolution surface mass balance map of Antarctica (1979-2010) based on regional atmospheric climate modeling, Geophys. Res. Lett., 39, L04501, https://doi.org/10.1029/2011g1050713, 2012.

Looyenga, H.: Dielectric constants of heterogeneous mixtures, Physica, 31, 401-406, https://doi.org/10.1016/00318914(65)90045-5, 1965.

Mavrocordatos, C., Attema, E., Davidson, M., Lentz, H., and Nixdorf, U.: Development of ASIRAS (Airborne SAR/Interferometric Altimeter System), in: IGARSS 2004, 2004 IEEE International Geoscience and Remote Sensing Symposium, 4, 2465-2467, https://doi.org/10.1109/IGARSS.2004.1369792, 2004.

Medley, B., Joughin, I., Das, S. B., Steig, E. J., Conway, H., Gogineni, S., Criscitiello, A. S., McConnell, J. R., Smith, B. E., Broeke, M. R., Lenaerts, J. T. M., Bromwich, D. H., and Nicolas, J. P.: Airborne-radar and ice-core observations of annual snow accumulation over Thwaites Glacier, West Antarctica confirm the spatiotemporal variability of global and regional atmospheric models, Geophys. Res. Lett., 40, 36493654, https://doi.org/10.1002/grl.50706, 2013.

Medley, B., Joughin, I., Smith, B. E., Das, S. B., Steig, E. J., Conway, H., Gogineni, S., Lewis, C., Criscitiello, A. S., McConnell, J. R., van den Broeke, M. R., Lenaerts, J. T. M., Bromwich, D. H., Nicolas, J. P., and Leuschen, C.: Constraining the recent mass balance of Pine Island and Thwaites glaciers, West Antarctica, with airborne observations of snow accumulation, The Cryosphere, 8, 1375-1392, https://doi.org/10.5194/tc8-1375-2014, 2014.

Morris, E. M.: A theoretical analysis of the neutron scattering method of measuring snow and ice density, J. Geophys. Res., 113, F03019, https://doi.org/10.1029/2007JF000962, 2008.

Morris, E. M., Mulvaney, R., Arthern, R. J., Davies, D., Gurney, R. J., Lambert, P., De Rydt, J., Smith, A. M., Tuckwell, R. J., and Winstrup, M.: Snow Densification and Recent Accumulation Along the iSTAR Traverse, Pine Island Glacier, Antarctica, J. Geophys. Res.-Earth Surf., 122, 2284-2301, https://doi.org/10.1002/2017JF004357, 2017.

Mouginot, J., Rignot, E., and Scheuchl, B.: Sustained increase in ice discharge from the Amundsen Sea Embayment, West Antarctica, from 1973 to 2013, Geophys. Res. Lett., 41, 15761584, https://doi.org/10.1002/2013GL059069, 2014.

Mouginot, J., Scheuchl, B., and Rignot, E.: MEaSUREs Antarctic Boundaries for IPY 2007-2009 from Satellite Radar, Version 2, Subset: Basins_Antarctica_v02, Boulder, Colorado USA, NASA National Snow and Ice Data Center Distributed Active Archive Center, https://doi.org/10.5067/AXE4121732AD, 2017.

Nicolas, J. P., Vogelmann, A. M., Scott, R. C., Wilson, A. B., Cadeddu, M. P., Bromwich, D. H., Verlinde, J., Lubin, D., Russell, L. M., Jenkinson, C., Powers, H. H., Ryczek, M., Stone, G., and Wille, J. D.: January 2016 extensive summer melt in West Antarctica favoured by strong El Niño, Nat. Commun., 8, 15799, https://doi.org/10.1038/ncomms15799, 2017.

Overly, T. B., Hawley, R. L., Helm, V., Morris, E. M., and Chaudhary, R. N.: Greenland annual accumulation along the EGIG line, 1959-2004, from ASIRAS airborne radar and neutron-probe density measurements, The Cryosphere, 10, 1679-1694, https://doi.org/10.5194/tc-10-1679-2016, 2016.

Richardson, C., Aarholt, E., Hamran, S.-E., Holmlund, P., and Isaksson, E.: Spatial distribution of snow in western Dronning 
Maud Land, East Antarctica, mapped by a ground-based snow radar, J. Geophys. Res.-Sol. Ea., 102, 20343-20353, https://doi.org/10.1029/97jb01441, 1997.

Rignot, E., Mouginot, J., and Scheuchl, B.: MEaSUREs InSARBased Antarctica Ice Velocity Map, Version 2, Boulder, Colorado USA, NASA National Snow and Ice Data Center Distributed Active Archive Center, https://doi.org/10.5067/D7GK8F5J8M8R, 2017.

Rignot, E., Mouginot, J., Scheuchl, B., van den Broeke, M., van Wessem, M. J., and Morlighem, M.: Four decades of Antarctic Ice Sheet mass balance from 1979-2017, P. Natl. Acad. Sci. USA, 116, 1095-1103, https://doi.org/10.1073/pnas.1812883116, 2019.

Scott, J. B. T., Smith, A. M., Bingham, R. G., and Vaughan, D. G.: Crevasses triggered on Pine Island Glacier, West Antarctica, by drilling through an exceptional melt layer, Ann. Glaciol., 51, 6570, https://doi.org/10.3189/172756410791392763, 2010.

Sinisalo, A., Anschütz, H., Aasen, A. T., Langley, K., von Deschwanden, A., Kohler, J., Matsuoka, K., Hamran, S.E., Øyan, M.-J., Schlosser, E., Hagen, J. O., Nøst, O. A., and Isaksson, E.: Surface mass balance on Fimbul ice shelf, East Antarctica: Comparison of field measurements and largescale studies, J. Geophys. Res.-Atmos., 118, 11625-11635, https://doi.org/10.1002/jgrd.50875, 2013.

Turner, J., Phillips, T., Thamban, M., Rahaman, W., Marshall, G. J., Wille, J. D., Favier, V., Winton, V. H. L., Thomas, E., Wang, Z., van den Broeke, M., Hosking, J. S., and LachlanCope, T.: The Dominant Role of Extreme Precipitation Events in Antarctic Snowfall Variability, Geophys. Res. Lett., 46, 35023511, https://doi.org/10.1029/2018GL081517, 2019.

U.S. Geological Survey: Landsat Image Mosaic of Antarctica (LIMA), Tech. rep., available at: http://pubs.er.usgs.gov/ publication/fs20073116 (last access: 25 April 2019), 2007. van Wessem, J. M., van de Berg, W. J., Noël, B. P. Y., van Meijgaard, E., Amory, C., Birnbaum, G., Jakobs, C. L., Krüger, K., Lenaerts, J. T. M., Lhermitte, S., Ligtenberg, S. R. M., Medley, B., Reijmer, C. H., van Tricht, K., Trusel, L. D., van Ulft, L. H., Wouters, B., Wuite, J., and van den Broeke, M. R.: Modelling the climate and surface mass balance of polar ice sheets using RACMO2 Part 2: Antarctica (1979-2016), The Cryosphere, 12, 1479-1498, https://doi.org/10.5194/tc-12-1479-2018, 2018.

Yamamoto, J. K.: An Alternative Measure of the Reliability of Ordinary Kriging Estimates, Math. Geol., 32, 489-509, https://doi.org/10.1023/A:1007577916868, 2000.

Yamamoto, J. K.: Correcting the Smoothing Effect of Ordinary Kriging Estimates, Math. Geol., 37, 69-94, https://doi.org/10.1007/s11004-005-8748-7, 2005.

Yamamoto, J. K.: On unbiased backtransform of lognormal kriging estimates, Comput. Geosci., 11, 219-234, https://doi.org/10.1007/s10596-007-9046-x, 2007.

Yamamoto, J. K.: Assessing Uncertainties for Lognormal Kriging Estimates, in: Proceedings of the 8th International Symposium on Spatial Accuracy Assessment in Natural Resources and Environmental Sciences: Accuracy in geomatics, edited by: Zhang, J. and Goodchild, M. F., Spacial accuracy 2008, World Academic Union (World Academic Press), Shanghai, China, 6269, 2008.

Zwally, H., Giovinetto, M. B., Beckley, M. A., and Saba, J. L.: Antarctic and Greenland Drainage Systems, GSFC Cryospheric Sciences Laboratory, available at: http://icesat4. gsfc.nasa.gov/cryo_data/ant_grn_drainage_systems.php (last access: 1 March 2021), 2012. 